\title{
On the temperature evolution during continuous laser-assisted tape winding of multiple C/PEEK layers: The effect of roller deformation
}

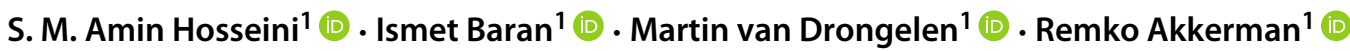

Received: 31 January 2020 / Accepted: 12 May 2020 / Published online: 30 June 2020

(C) The Author(s) 2020

\begin{abstract}
Laser-assisted tape winding (LATW) is a highly automated process for manufacturing tubular-like fiber-reinforced thermoplastic composites such as flywheels and pipes. One of the crucial parameters in the LATW process is the temperature of the nip point at which the incoming prepreg tape is bonded with the substrate by a compaction roller. Therefore, the temperature evolution of the nip point plays a significant role to have a proper consolidation at the tape-substrate interface. The nip point temperature is highly affected by the time-dependent geometry of the substrate and roller during continuous LATW of thick composite rings. In this paper, a critical assessment of the substrate and tape surface temperature evolution is investigated experimentally by means of a thermal camera during the LATW process of a 26-layers thick carbon/PEEK composites. A three-dimensional (3D) optical model is coupled with a thermal model in which the substrate computational domain is updated with respect to the deposited tapes. A good agreement is found between the measured and predicted tape and substrate temperatures. The total absorbed heat and heated length of the substrate and tape are described based on the roller deformation. An increase in tape and substrate nip point temperatures is found with an increase in roller deformation during consecutive winding. It is also found that the consolidation pressure and contact length at the roller-substrate interface increases during the winding process. Accordingly, the heat transfer coefficient at the roller-substrate interface is studied using the developed process model.
\end{abstract}

Keywords Tape winding $\cdot$ Prepreg $\cdot$ Process simulation $\cdot$ Thermal analysis $\cdot$ Laser

\section{Introduction}

Continuous fiber-reinforced thermoplastic composites such as C/PEEK (carbon/poly ether-ether-ketone) are considered in potential applications where high mechanical performance and lightweight design are required for structural elements used in e.g. aerospace, aircraft or energy storage

Ismet Baran

i.baran@utwente.nl

S. M. Amin Hosseini

s.m.a.hosseini@utwente.nl

Martin van Drongelen

m.vandrongelen@utwente.nl

Remko Akkerman

r.akkerman@utwente.nl

1 Faculty of Engineering Technology, Chair of Production Technology, University of Twente, NL, 7500AE, Enschede, The Netherlands
[24]. There are various manufacturing techniques to produce continuous fiber-reinforced thermoplastic composites such as press and/or stamp forming, automated fiber placement (AFP), automated tape winding (ATW), autoclave consolidation, etc.

The ATW technique is highly automated and used to manufacture tubular-like structures such as flywheel rotors $[21,38]$, tanks for energy storage, pipes for oil and gas industry $[29,44]$, tubes for bikes, etc. The heating source can be a hot gas torch [12, 13, 22], infrared lamp [4, 16, 18], near-infrared (NIR) diode lasers [5, 10, 11, 31], and recently LED heating [25]. The parts are built up layer by layer onto a rotating mandrel in the ATW processes. The prepreg tape and the laid down substrate are locally molten by the heat source before touching each other at the nip point which can be seen schematically in Fig. 1. In-situ consolidation which is the main mechanism to form the final product takes place at the nip point vicinity where the melted incoming tape and substrate bond to each other by means of a compaction roller [17]. Consolidation includes the development of intimate contact and then healing of the 


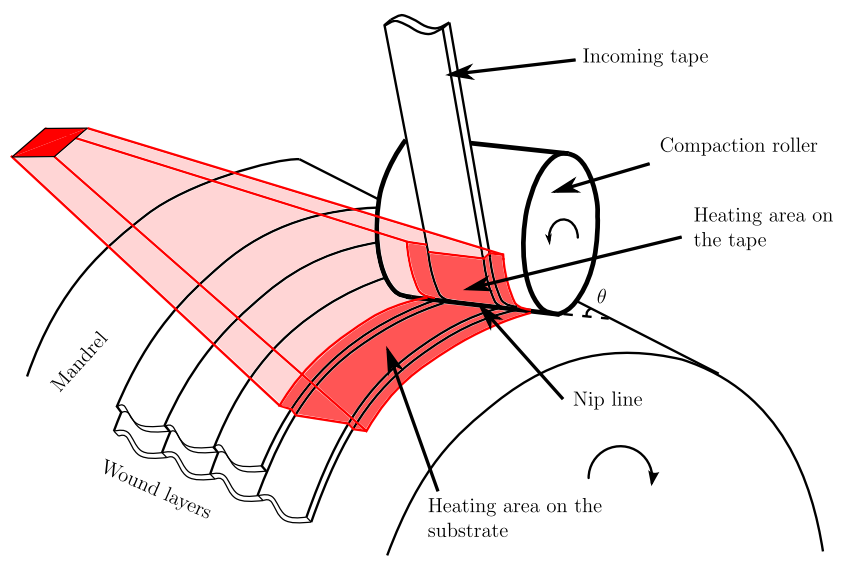

Fig. 1 A schematic view of the LATW process

polymeric matrix. Both phenomena are highly temperaturedependent processes and especially it is very challenging during depositing multiple layers since the substrate is exposed to multiple heating and cooling cycles during the manufacturing process. In addition, the absorption and reflection of the laser light by the substrate and tape material is highly anisotropic due to the presence of the fibers which influences the heating behavior of the materials. It is therefore a difficult task to control the process temperature which together with the applied pressure and the corresponding dwell time affects the consolidation quality and the mechanical performance of the final part. It was shown in [37] that a high process temperature resulted in a reduction in the wedge peel strength of the carbonreinforced polyamide 6 (C/PA6) composites manufactured by the LATP process. On the other hand, a proper bonding was achieved for consolidation temperatures lower than the melting point of the C/PEEK material produced by LATP process in [35].

Several experimental and numerical modeling studies were conducted to understand, describe and predict the process temperature during the AFP and ATW processes. An in-situ thermographic analysis was carried out in [7, 9, $15,30]$ by utilizing an AFP process. Significant temperature gradients were found for the deposited regions having overlapped tows, gaps and twists. The through-thickness temperature in between the deposited layers was measured by using thermocouples in [28] for a LATW process. The measured temperature was compared with the opticalthermal model predictions. An analytical thermal model was developed in [40] for a LATP process. It was found that the through-thickness temperature was significantly affected by the high process speed. The same analytical approach was used in [41] and an inverse analytical method was developed to obtain the desired heat flux distribution on the tape surfaces for a desired processing temperature. The heat power and placement speed were correlated with the process temperature considering the roller deformation in [8]. A semi-empirical thermal model was developed and validated with the experiments. An optical-thermal model was developed in [43] for a LATW process. The effect of winding angle on the nip point temperature was investigated. The effect of the deformed geometry, temperature and thermal contact resistance of the roller on the process temperature was studied in [36] by using a thermal process model. The presence of the shaded region for the non-deformed roller resulted in a lower surface temperature prior to the nip point.

Specific attention was given to the placement and winding of multiple layers in the literature to investigate the effect of previously placed or wound layer on the process temperature as summarized in the following. The continuous hoop winding of glass/polypropylene and carbon/epoxy tapes was studied in [39] and [13], respectively. The temperature evolution during continuous deposition of multiple layers on a cylindrically shaped mandrel was captured by a thermal model and the predictions were compared with the measurements. The analysis of the temperature and degree of cure for hoopwound cylinders was carried out in [4] for graphite/epoxy and glass/epoxy composites. The radiative surface heating was found to be more significant for the glass/epoxy composites than the graphite/epoxy composites. The in-situ curing of graphite/epoxy taped during continuous winding was modeled in [18] by using a thermo-chemical process model. It was found that the winding speed had a significant effect on the degree of cure of the material. A thermomechanical model was developed in [6] to predict the process-induced thermal residual stresses in a continuous winding of multiple carbon/PEEK layers. The mandrel properties and the tape tension were found to be effective parameters for the development of residual stress. The effect of growing thickness in a continuous LATW process was studied numerically in [14]. The evolution of peak temperature was investigated during continuous deposition of C/PEEK tapes. The adjacent placement of a carbon epoxy prepreg with an IR heater was studied in [23]. A significant temperature increase perpendicular to the placement path was obtained experimentally and numerically. A surrogate process model was developed in [27] for the simulation of multiple placement of C/PA6 tapes. The laser power and placement velocity were found to be the most effective parameters.

Recently, the anisotropic reflection behavior of the laser beams was considered in the process modeling studies [26, $33,34,42]$. A comprehensive 3D reflection model was developed in [34] for carbon fiber reinforced thermoplastic composite tapes. A "micro-half-cylinder" model was implemented in a CAD model which was subsequently used in OptiCAD software to simulate the anisotropic reflective 
Table 1 Overview of the studies focusing on the multiple placement/winding of layers and the roller deformation for the investigation of temperature development in AFP and ATW processes

\begin{tabular}{|c|c|c|c|c|c|c|}
\hline $\begin{array}{l}\text { Process } \\
\text { - Ref. }\end{array}$ & $\begin{array}{l}\text { Roller } \\
\text { deformation }\end{array}$ & $\begin{array}{l}\text { Deposited } \\
\text { layers }\end{array}$ & $\begin{array}{l}\text { Heat } \\
\text { source }\end{array}$ & $\begin{array}{l}\text { Heat flux } \\
\text { modeling }\end{array}$ & $\begin{array}{l}\text { Temperature } \\
\text { measurement }\end{array}$ & Composite \\
\hline ATW [6] & No & Multiple & Laser beam & Specular ray tracing & Thermocouple & $\mathrm{C}(\mathrm{IM} 7) / \mathrm{PEEK}, V_{f}=60 \%$ \\
\hline AFP [33] & Yes & Single & NIR diode laser & Anisotropic ray tracing & IR camera, Thermocouple & AS4/PEEK, $V_{f}=55 \%$ \\
\hline AFP [36] & Yes & Single & NIR diode laser & Uniform heat flux & IR camera, Thermocouple & AS4/PEEK, $V_{f}=55 \%$ \\
\hline ATW [13] & No & Multiple & Hot gas torch & Convective & Thermocouple & AS4/epoxy \\
\hline ATW [39] & No & Multiple & Hot gas torch & Convective & Pyrometer & $\mathrm{G} / \mathrm{PP}, W_{f}=70 \%$ \\
\hline ATW [4] & No & Multiple & Infrared heating & Radiative & N/A & graphite/epoxy, S-glass/epoxy \\
\hline ATW [18] & No & Multiple & Infrared heating & Radiative & N/A & graphite/epoxy \\
\hline ATW [14] & No & Multiple & NIR diode laser & Anisotropic ray tracing & IR camera & C/PEEK \\
\hline AFP [23] & No & Multiple & IR heating & Radiative & IR camera, Thermocouple & Toray T800S/3900-2 \\
\hline AFP [27] & No & Multiple & NIR diode laser & Specular ray tracing & IR camera, Thermocouple & PA-6/carbon \\
\hline ATW [28] & No & Multiple & NIR diode laser & Anisotropic ray tracing & IR camera, Thermocouple & PA12/carbon $V_{f}=45 \%$ \\
\hline
\end{tabular}

behavior of tapes. The same optical model was used in [33] to predict the temperature distribution in an AFP process in which the roller deformation was taken into account. The anisotropic reflection behavior of the prepreg tapes for the LATW process was studied in [26] in which a bidirectional reflectance distribution function (BRDF) was employed to estimate the heat flux distributions on the substrate and tape by taking the fiber orientation into account. The effect of specular and anisotropic reflection of the laser irradiation on the process temperature was studied numerically in [42].

A summary of the aforementioned literature survey focusing on multiple placement/winding taking the roller deformation into account is listed in Table 1 with important aspects based on the utilized experimental techniques and process models. Although there have been several works carried out to analyze the temperature evolution during ATW and AFP processes, the influence of the roller deformation evolution and local geometry change during winding of multiple layers on the temperature history has not been studied as seen from Table 1 .
A critical assessment of the temperature development in the vicinity of the nip point by taking the local geometry change into account is essential to ensure a proper final product quality. In this paper, the temperature near the nip point region is analyzed by employing a thermal camera. The change in the nip point location due to the roller deformation is captured by performing an image analysis. The roller deformation and resulting increase in the consolidation pressure and length are described by using a pressure-sensitive film. A coupled optical-thermal process model is developed to predict the influence of the roller deformation on the temperature evolution. The already developed optical model [26] is used to estimate the anisotropic reflection behavior of the incoming laser rays. The roller deformation and the local geometry change near the nip point are considered in the 3D optical model. The growing substrate thickness during the multiple winding of the incoming C/PEEK tapes is taken into account in the 2D thermal model by updating the computational domain. A parameter study is performed based on the heat transfer
Fig. 2 A view of the AFP machine during LATW process

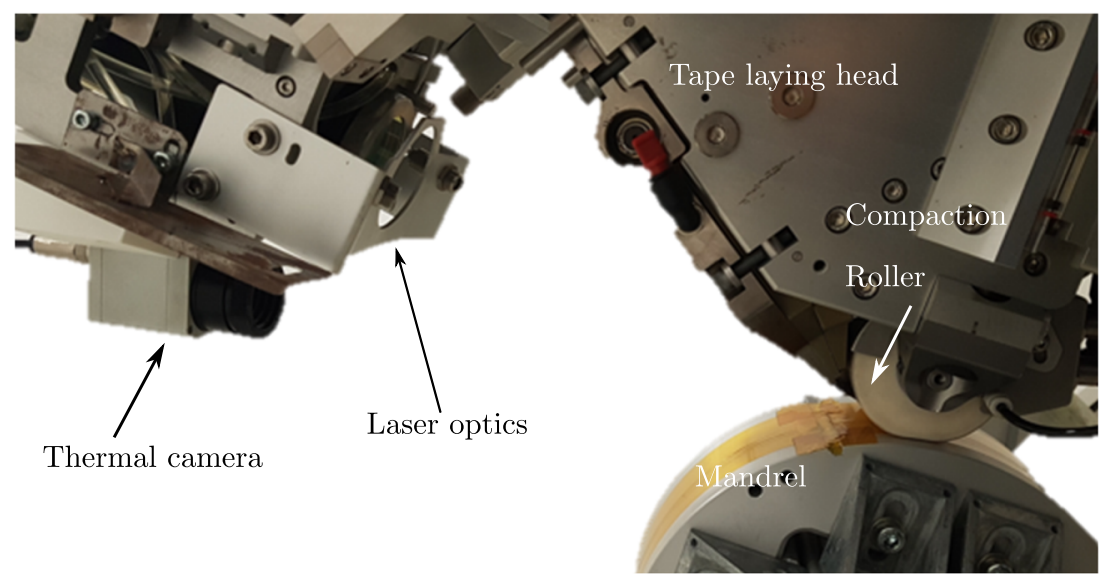


Fig. 3 Model geometry used for the optical model (reproduced with permission from [26])

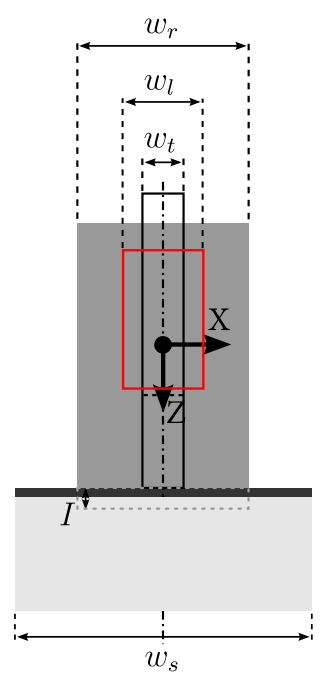

Front view
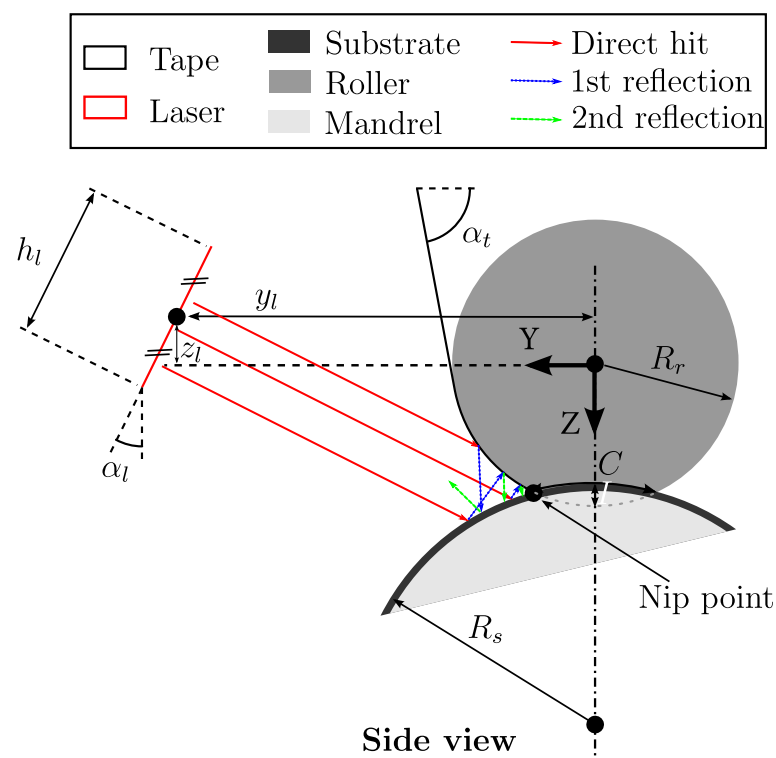

at the interface between the roller and substrate using the developed process model and results are compared with the temperature measurements.

\section{Experimental}

The prepreg material used in the LATW process was TC1200 AS-4/PEEK provided by TenCate with a fiber volume content of $59 \%$ and a nominal thickness and width of $t_{p}=$ $0.15 \mathrm{~mm}$ and $w_{p}=6.35 \mathrm{~mm}$, respectively. The roller was made of solid polytetrafluoroethylene (PTFE) with 40 shore hardness. The mandrel was made from Al-6082-T6 anodized aluminum. The winding surface was covered by a polyimide (Kapton ${ }^{\circledR}$ ) tape with a silicone adhesive coating to improve the adhesion for the first layer [2].

Three thick rings were manufactured using the Coriolis Composites AFP machine for reliability and repeatability of
Table 2 Optical and geometrical reference values used in simulating the LATW process

\begin{tabular}{llll}
\hline & Symbol & Value & Description \\
\hline Roller & $R_{r}$ & $35 \mathrm{~mm}$ & Roller radius \\
& $w_{r}$ & $50 \mathrm{~mm}$ & Roller width \\
& $n_{r}$ & 1.4 & Roller refractive index[26] \\
& $I$ & $2 \mathrm{~mm}$ & Roller indentation into mandrel surface \\
& $C$ & $22 \mathrm{~mm}$ & Arc length of roller contact with substrate \\
Tape & $w_{t}$ & $6.35 \mathrm{~mm}$ & Tape width \\
& $L_{t a p e}$ & $40 \mathrm{~mm}$ & Considered length of the tape \\
& $\alpha_{t}$ & $60^{\circ}$ & Laying tape angle \\
& $n_{t}$ & 1.8 & Tape refractive index [10] \\
& $R_{S}$ & $122 \mathrm{~mm}$ & Substrate radius \\
& $w_{s}$ & $6.35 \mathrm{~mm}$ & Substrate width \\
& $L_{s u b s}$ & $767 \mathrm{~mm}$ & Considered length of the substrate (Mandrel circumference) \\
& $\phi_{s}$ & $0^{\circ}$ & Substrate fiber orientation \\
& $n_{s}$ & 1.8 & Substrate refractive index [10] \\
& $y_{l}$ & $-308.61 \mathrm{~mm}$ & Laser spot y-position (of centroid) \\
& $z_{l}$ & $111.93 \mathrm{~mm}$ & Laser spot z-position (of centroid) \\
& $h_{l}$ & $28 \mathrm{~mm}$ & Laser spot height \\
& $w_{l}$ & $11 \mathrm{~mm}$ & Laser spot width \\
& $\alpha_{l}$ & $-20.89^{\circ}$ & Laser beam angle \\
& $N_{0}$ & 4000 & Number of rays launched from the laser source \\
& $N_{r}$ & 5 & Number of reflected rays per incident used in optical model [26] \\
\hline
\end{tabular}


the temperature measurements. The AFP machine consisted of an industrial robot with six degrees of freedom, onto which a tape laying head (end-effector) was mounted. A side view of the tape laying head and its components during the winding process are shown in Fig. 2. A schematic view of the tape laying head describing the position of individual parts is depicted in Fig. 3. The reference values for geometrical parameters are listed in Table 2.

The NIR laser with a wavelength of $980 \mathrm{~nm}$ was used. The laser beam was homogenized to yield a near-uniform (top-hat) power distribution. The roller was pressed onto the substrate using a controlled nominal force of $435 \mathrm{~N}$. A maximum of 5 continuous layers was allowed to be deposited due to the limitation of the AFP machine. After every 5 layers, the machine cut the tape, shut down the laser and moved to the starting position. Once the ring temperature reached approximately room temperature the winding process was resumed. A total of 26 layers were wound for each ring including one layer as the base and 5 continuous layers repeated 5 times.
The temperature on the substrate and tape surface, at the heating region close to the nip point was measured by an IR thermal camera. The thermal camera was a MicroEpsilon thermalIMAGER TIM 400 with a resolution of $382 \times 288$ pixels. The thermal camera spectrum range $(7.5-$ $13 \mathrm{~mm}$ ) did not interfere with the laser beam wavelength $(0.98 \mathrm{~mm})$, therefore, the reflectance of the laser beam toward the thermal camera did not affect the temperature readings. The camera was mounted to the tape laying head just below the laser source (visible in Fig. 2). It constantly measured the infrared radiation emitted by the material near the nip point vicinity with $80 \mathrm{~Hz}$. Continuous video streams of the thermal field for the substrate and tape surfaces were extracted from the camera. To illustrate, a single frame of the measured temperature distribution is shown in Fig. 4a. The temperature was logged and averaged in time over a $3 \times 1$ pixels (width $\times$ height) at the center of tape and substrate width, as seen by rectangular boxes in Fig. 4a.

The size of a pixel at object level is known as Instantaneous Field of View (IFOV) which is defined based
Fig. 4 a Thermographic image captured by IR thermal camera. White boxes are the schematic measuring areas where the temperature is averaged with 3 pixels in width $(x)$ and 1 pixel in winding $(y)$ directions. b A schematic view of the pixels with respect to the camera position and the actual size of the pixel due to curved geometry. c The actual pixel size distribution on the tape and substrate surface

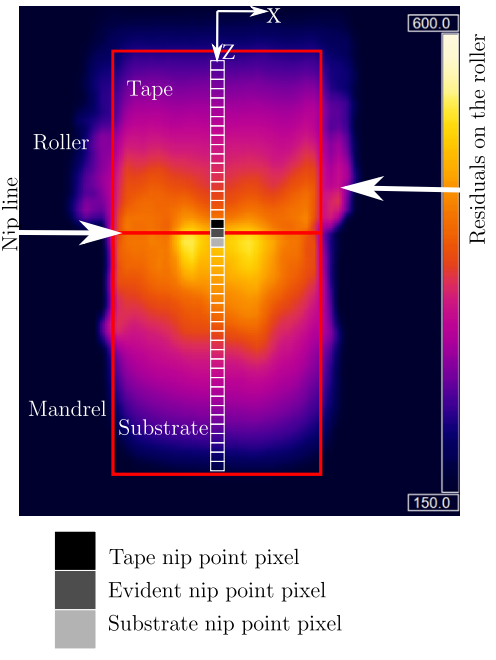

(a)

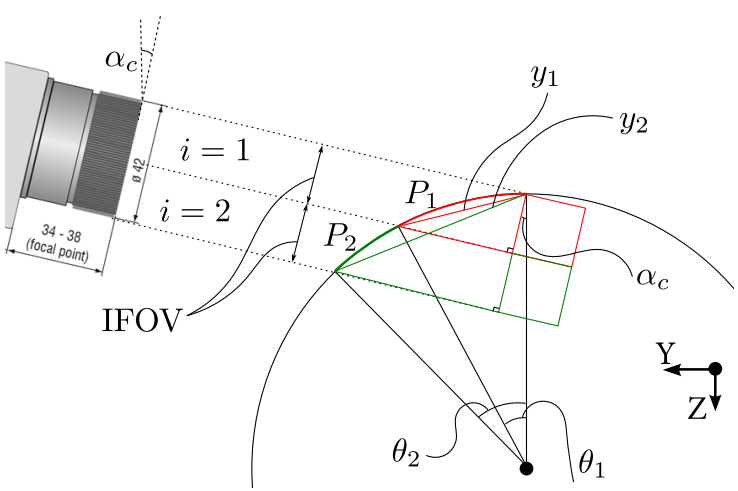

(b)

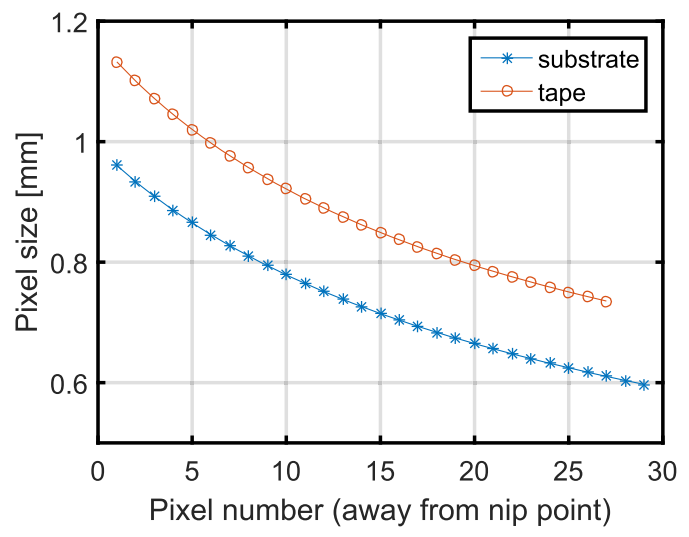

(c) 
on the lens type and the distance to object [1]. Due to the curvature of the substrate and tape, the distance to the thermal camera lens varied, therefore the actual pixel size also varied in the winding direction. Moreover, the orientation of the camera with respect to the measuring pixel (IFOV) caused extra nonlinearity to the actual pixel size. The schematic position of the thermal camera together with two exemplary measuring pixels are plotted in Fig. 4b for the substrate. The covered arc length by the two selected pixels are shown by $P_{1}$ (red) and $P_{2}$ (green) which correspond to the actual size of the pixels on the object. The actual pixel length $P_{1}$ was closer to the nip point and covered larger area of the substrate than $P_{2}$ which was located further from the nip point. The arc length for each pixel $i$ was calculated by the following expression:

$P_{i}=R_{S}\left(\theta_{i}-\theta_{i-1}\right)$

where $R_{S}$ was the substrate radius, $\theta_{i}$ and $\theta_{i-1}$ were the current and previous pixel angle in radians $\theta_{i=0}=0$ radians). In order to calculate $\theta_{i}$, the corresponding length of the line segment $\left(y_{i}\right)$ seen in Fig. $4 \mathrm{~b}$ was calculated as:

$y_{i}=2 R_{s} \sin \left(\theta_{i} / 2\right)$

The length of the line segment $y_{i}$ was represented also based on the size of the measuring pixel (IFOV) and the rotation angle of the camera with respect to the $Z$-axis $\alpha_{c}$ as:

$y_{i}=\frac{i \times I F O V}{\sin \left(\theta_{i} / 2 \alpha\right)}$

By combining (2) and (3), the following expression can be derived for $\theta_{i}$ :

$\sin (\theta / 2) \sin \left(\theta_{i} / 2+\alpha\right)=\frac{i \times I F O V}{2 R_{S}}$

The calculated nonlinear pixel size variation for $\alpha=10^{\circ}$ is depicted in Fig. $4 \mathrm{c}$ for the current experimental setup.

Finally, the pressure-sensitive films were used to estimate the roller deformation and the resulting increase in the consolidation pressure and length for different substrate thicknesses.

\section{Thermal-optical model}

\section{Optical model}

The anisotropic reflection behavior of the fiber-reinforced composites tapes can be modeled either $i$ ) by physically modeling the microstructure of surface defined by microhalf cylinders and applying a specular ray tracing approach as done in $[33,34]$ by using the non-sequential ray tracing software (OptiCAD 10), or ii) by defining a special function or material model that takes the fiber orientation into account and using it within the ray tracing approach as done in [26]. The first approach takes relatively long computation time, however relatively high accuracy can be obtained for the reflection behavior. On the other hand, the second approach is relatively fast, however, it requires input parameters to define the reflection behavior. The work carried out by Reichardt et al. [26] was the basis of the current 3D optical model since it was computationally fast. The anisotropic reflection behavior of the laser rays reflection and varying beam incident angle due to the cylindrical curvature was considered on the optical model.

A total of 4000 laser rays were defined at the location of the laser source using the Sobol sampling [32]. The ray incident location was then calculated based on the ray tracing technique considering the tape, substrate, and roller triangulated geometries. Then, the anisotropic reflection and absorption at the material surface were calculated. The reflected light was modeled by generating new rays considering the bidirectional reflectance distribution function (BRDF) which is based on microfacet theory [3]. Two consecutive reflections were considered using the BRDF in the present paper. The details of the optical model and its implementation can be found in [26]. The output of the optical model was a 2D surface heat flux distribution $q_{i}^{\prime \prime}$ (laser power per unit area) with a mesh size of $1 \mathrm{~mm}$ in width and winding directions. The obtained heat flux from the optical model was used as an input boundary condition in the thermal model.

The roller deformation was considered in this study as a geometrical effect. The roller deformation was modeled by introducing the indentation parameter $I$ in the 3D optical model as seen in Fig. 3. The local geometry change at the nip point vicinity affects the laser heat flux distribution calculated by the 3D optical model, e.g. the shadow area formed by the roller on the substrate reduces as the roller deformation increases. The direction of the indentation was in the $Z$-direction. The location of the nip point, therefore,

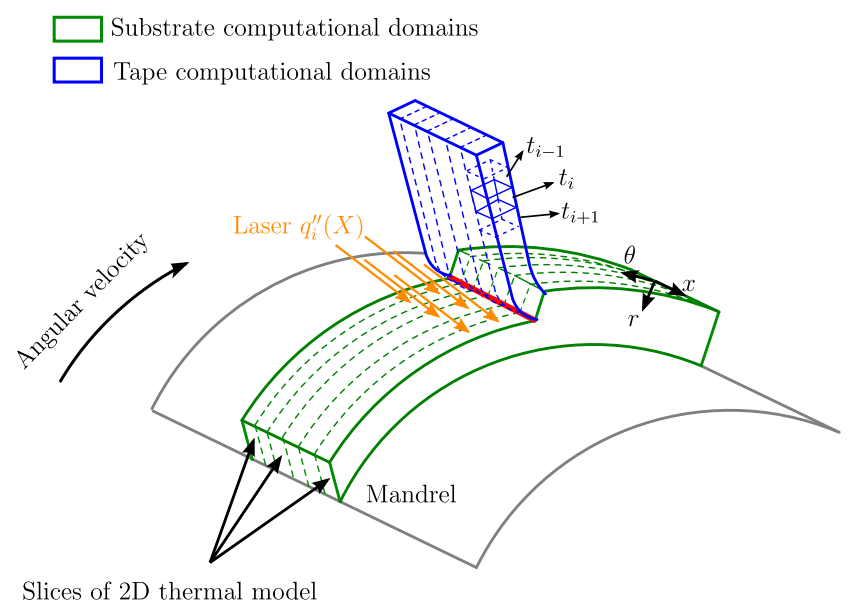

Fig. 5 A schematic view of the 2.5D substrate and tape thermal domains 
changed both in $Z$ - and $Y$-direction. Note that the location of the laser spot was also changed since the laser had moved simultaneously with the roller as seen in Fig. 2. The resulting consolidation length (i.e. the arc length denoted as $C$ in Fig. 3) of the interface between the roller and substrate was estimated based on the geometrical configuration and $I$ by using the following equation:

$$
C=R_{s} \cos ^{-1}\left(\frac{R_{s}+R_{r}-I}{2 R}+\frac{R_{s}^{2}-R_{r}^{2}}{2 R_{s}\left(R_{s}+R_{r}-I\right)}\right)
$$

The initial value of $I$ was determined experimentally for layer 2, i.e. winding on a 1-layer substrate. After winding of each layer it was assumed that $I$ increased with $0.15 \mathrm{~mm}$ which was the thickness of a single layer. To illustrate, the total indentation was therefore defined as $I+25 \times 0.15 \mathrm{~mm}$ for layer 26.

\section{Heat transfer model}

Multiple slices of tape and substrate thermal domains were defined adjacent to each other in the width direction, i.e. $x$-direction as seen in Fig.5. Thus, a 2.5D thermal model was obtained in which the 3D temperature distribution was predicted while the in-plane conduction in the width direction ( $x$-direction) was neglected. Note that a local
Fig. 6 Schematic view of the thermal model in winding and thickness direction for (a) the growing substrate and (b) the incoming tape together with the applied boundary conditions

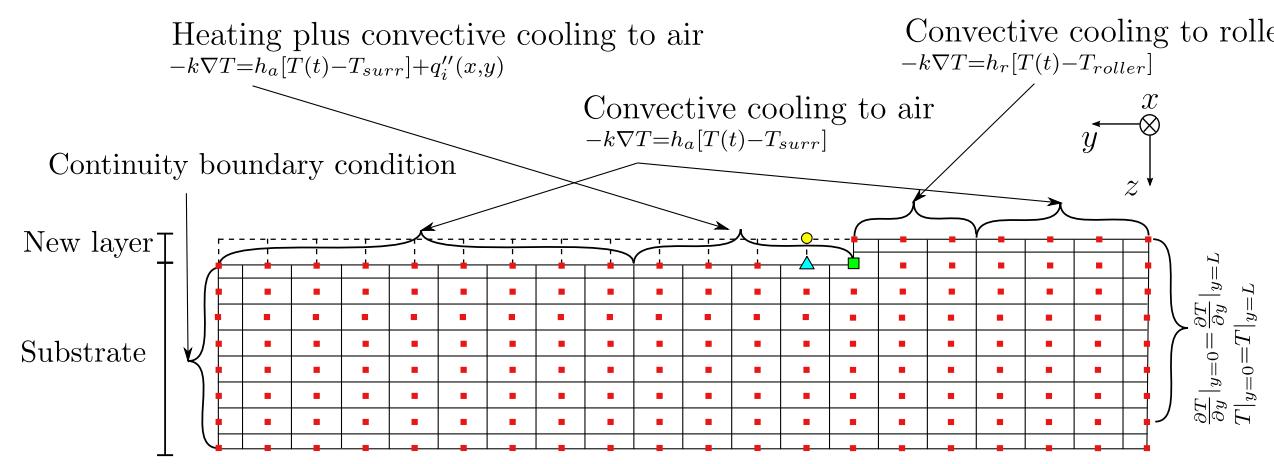

Convective cooling to mandrel $-k \nabla T=h_{m}\left[T(t)-T_{\text {mandrel }}\right]$

$\mathrm{L}=$ Mandrel circumference

- Current nip point

- Tape temperature at next material step

$\triangle$ Nip point at the next $\mathrm{step}=($ substrate temperature + tape temperature $) / 2$

(a)

Feeding direction

Convective cooling to the roller: $-k \nabla T=h_{t r}\left[T(t)-T_{\text {roller }}\right]$
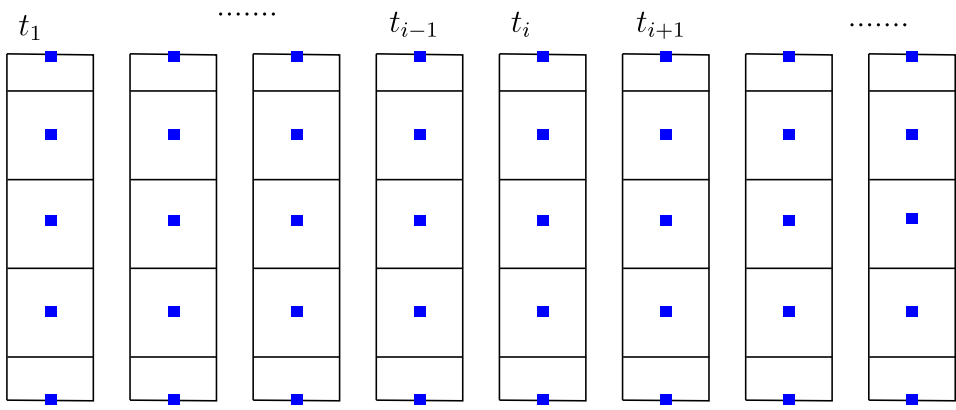

Heating plus convective cooling to air: $-k \nabla T=h_{a}\left[T_{s u r r}-T(t)\right]+q_{i}^{\prime \prime}(x, y)$

Considered incoming tape length

(b) 
Table 3 Overview of the prepreg thermal properties [33, 36]

\begin{tabular}{lllll}
\hline $\begin{array}{l}\text { Temperature } \\
\left({ }^{\circ} \mathrm{C}\right)\end{array}$ & $\begin{array}{l}\text { Specific heat } \\
\text { capacity } \\
\left(\mathrm{J} / \mathrm{kg} /{ }^{\circ} \mathrm{C}\right)\end{array}$ & $\begin{array}{l}\text { Density } \\
\left(\mathrm{Kg} / \mathrm{m}^{3}\right)\end{array}$ & $\begin{array}{l}\text { Conductivity in } \\
\text { fiber direction } \\
\left(\mathrm{W} / \mathrm{m} /{ }^{\circ} \mathrm{C}\right)\end{array}$ & $\begin{array}{l}\text { Conductivity } \\
\text { transverse to fiber } \\
\text { direction }\left(\mathrm{W} / \mathrm{m} /{ }^{\circ} \mathrm{C}\right)\end{array}$ \\
\hline 0 & 800 & 1601 & 3.5 & 0.42 \\
50 & 930 & 1598 & 4.6 & 0.52 \\
100 & 1040 & 1593 & 5.1 & 0.6 \\
150 & 1260 & 1586 & 5.9 & 0.7 \\
200 & 1300 & 1575 & 5.9 & 0.7 \\
250 & 1400 & 1563 & 6.1 & 0.7 \\
300 & 1550 & 1551 & 6.7 & 0.75 \\
350 & 1650 & 1537 & 6.8 & 0.68 \\
400 & 1700 & 1524 & 7.0 & 0.65
\end{tabular}

coordinate system was used specifically for the substrate. For each layer, the tape temperature was calculated before the substrate calculation. The tape nip point temperature was then forwarded to the growing substrate model. The substrate 2D cylindrical thermal domain was simplified to a Cartesian coordinate system via unfolding the cylindrical domain. The 1D tape domains in thickness $\left(z^{-}\right)$direction traveling in winding $(y-)$ direction were considered in each slice of the incoming tape as shown in Fig. 5. The 2D transient heat conduction problem in Cartesian $y$ - and $z$ directions is based on the following governing equation:

$\rho c_{p} \frac{\partial T}{\partial t}=\frac{\partial}{\partial y}\left(k_{y} \frac{\partial T}{\partial y}\right)+\frac{\partial}{\partial z}\left(k_{z} \frac{\partial T}{\partial z}\right)$

where $\rho$ is the density, $c_{p}$ is the specific heat capacity, $k_{y}$ and $k_{z}$ are the thermal conductivity in the winding and transverse direction, respectively. The influence of radiation terms and crystallization enthalpy were also neglected since the effects were insignificant compared to laser heat flux [36]. For the tape, the $\frac{\partial}{\partial y}\left(k_{y} \frac{\partial T}{\partial y}\right)$ term was omitted from Eq. 6 since the 1D tape domains neglect the in-plane thermal conductivity. Note that a local coordinate system different than the substrate was used specifically for the tape.
A schematic view of the computational domain for the substrate and tape is depicted in Fig. 6. It is seen that a 3D domain was obtained by considering the sliced geometry in Fig. 5 for the tape and substrate. The control volumebased finite difference (CV/FD) model was developed using an explicit scheme considering a Lagrangian frame to solve the governing equation. Total of $5 \mathrm{CVs}$ per layer were used in $z$-direction. A constant time step of $\Delta t=2 m s$ was chosen to have a stable solution for the explicit solver. A similar optical mesh size of $1 \mathrm{~mm}$ was used in the $x$ and $y$-directions. Therefore, the consistency of the coupling between the optical and thermal model was maintained. To model incoming tape deposition, 4 new CVs were added to the substrate computational domain based on the defined $\Delta t$ and $v$. Accordingly, the applied heat flux on the substrate surface was shifted in $y$-direction to simulate the moving heat flux. As indicated in Fig. 6a, the nip point at the next step is shown by the triangle and the tape temperature is indicated as a yellow circle. The nip point temperature was updated by averaging of the already calculated tape and the substrate temperature at the nip point.

The computational description of the tape domain is depicted in Fig. 6b where the tape initial temperature was equal to the $T\left(t_{1}\right)=T_{\text {surr }}$. The $1 \mathrm{D}$ thermal domain moved

Table 4 Overview of the reference values for the input parameters in the thermal simulation [12, 33, 36, 39]

\begin{tabular}{llll}
\hline Symbol & Value & Unit & Description \\
\hline$T_{\text {surr }}$ & 30 & ${ }^{\circ} \mathrm{C}$ & Surrounding temperature and the initial temperature of the incoming tape and substrate \\
$T_{\text {roller }}$ & $50[33]$ & ${ }^{\circ} \mathrm{C}$ & Roller temperature \\
$T_{\text {mandrel }}$ & 30 & ${ }^{\circ} \mathrm{C}$ & Mandrel temperature \\
$h_{a}$ & $20[39]$ & $\mathrm{W} \mathrm{m}^{-2}{ }^{\circ} \mathrm{C}^{-1}$ & Composite-air coefficient \\
$h_{t r}$ & $40[12]$ & $\mathrm{W} \mathrm{m}^{-2}{ }^{\circ} \mathrm{C}^{-1}$ & Tape-roller convection coefficient \\
$h_{r}$ & $1000[36]$ & $\mathrm{W} \mathrm{m}^{-2}{ }^{\circ} \mathrm{C}^{-1}$ & Substrate-roller convection coefficient \\
$h_{m}$ & 4000 & $\mathrm{~W} \mathrm{~m}^{-2}{ }^{\circ} \mathrm{C}^{-1}$ & Substrate-mandrel convection coefficient \\
\hline
\end{tabular}


Fig. 7 Cross-section of the produced ring

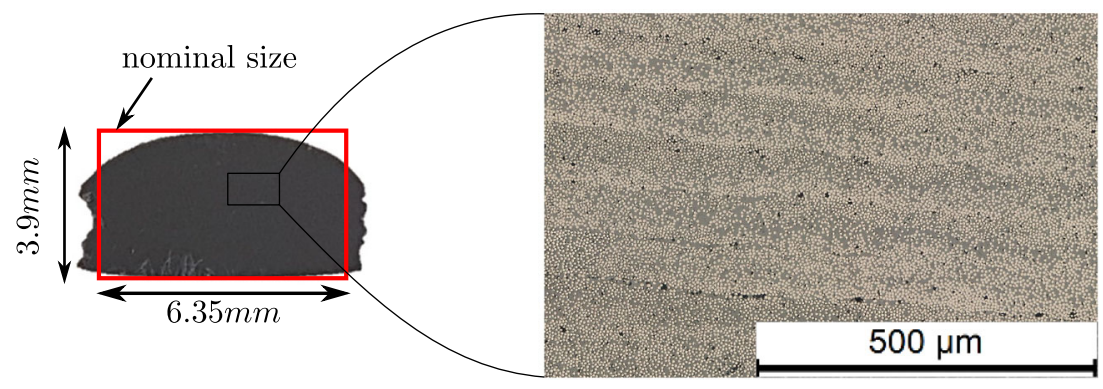

in winding $(y-)$ direction for $v \times \Delta t$ in each time step. As the 1D thermal domain traveled toward the nip point, the temperature distribution evolved at each timestamp $\left(t_{i}\right)$.

The physical body of the roller and mandrel were not modeled, however, their effect was taken into account by defining a convective heat transfer at the tape-roller, substrate-roller, and substrate-mandrel interfaces. Perfect thermal contact between the deposited layers was assumed in the thermal model since the thermal contact resistance between the layers is negligible [20]. The boundary conditions used in the thermal model are summarized in the following:

- Laser irradiation $\left(-k \nabla T=q_{i}^{\prime \prime}(x, y)\right)$ : The heat flux obtained from the optical model $\left(q_{i}^{\prime \prime}(x, y)\right)$ was applied at the tape and substrate surfaces.

- Tape-roller interface $\left(-k \nabla T=h_{t r}\left(T-T_{\text {roller }}\right)\right)$ : Convective heat transfer was defined at the tape-roller interface $\left(L_{\text {tape }}\right)$ using a heat transfer coefficient of $h_{t r}$ and roller temperature $T_{\text {roller }}$. The tape was always in contact with the roller at $z=t_{p}$ during heating.
- Substrate-roller interface $\left(-k \nabla T=h_{r}\left(T-T_{\text {roller }}\right)\right)$ : Convective heat transfer was defined at the substrateroller interface using a heat transfer coefficient $h_{r}$.

- Substrate-mandrel interface $\left(-k \nabla T=h_{m}(T-\right.$ $\left.T_{\text {mandrel }}\right)$ ): Convective heat transfer using a heat transfer coefficient of $h_{m}$ and mandrel temperature $T_{\text {mandrel }}$.

- Convective cooling to air $\left(-k \nabla T=h_{a}(T-\right.$ $\left.T_{\text {surr }}\right)$ ): Convective heat transfer using a heat transfer coefficient of $h_{a}$ and surrounding temperature $T_{\text {surr }}$ was applied at the tape and substrate surfaces.

- Continuity boundary condition: The temperatures and corresponding temperature gradients for the substrate surfaces at $y=0$ and $y=s u b s$ were defined as equal.

The temperature-dependent thermal properties of the C/PEEK tape were used in the thermal model which were taken from $[33,36]$ and listed in Table 3. The input parameters for the thermal model is listed in Table 4. The heat transfer coefficients and the corresponding temperatures were selected based on the reported values
Fig. 8 Thermal camera measurement during continuous winding of layers 22 to 26 for the visible nip point and at the 5 th pixel away from the nip point on the tape and substrate surfaces. The 5 th pixel roughly located at $4 \mathrm{~mm}$ and $2.2 \mathrm{~mm}$ away from the nip point for the substrate and tape, respectively. The dashed lines show the value and the duration where the temperature was averaged for the corresponding layer

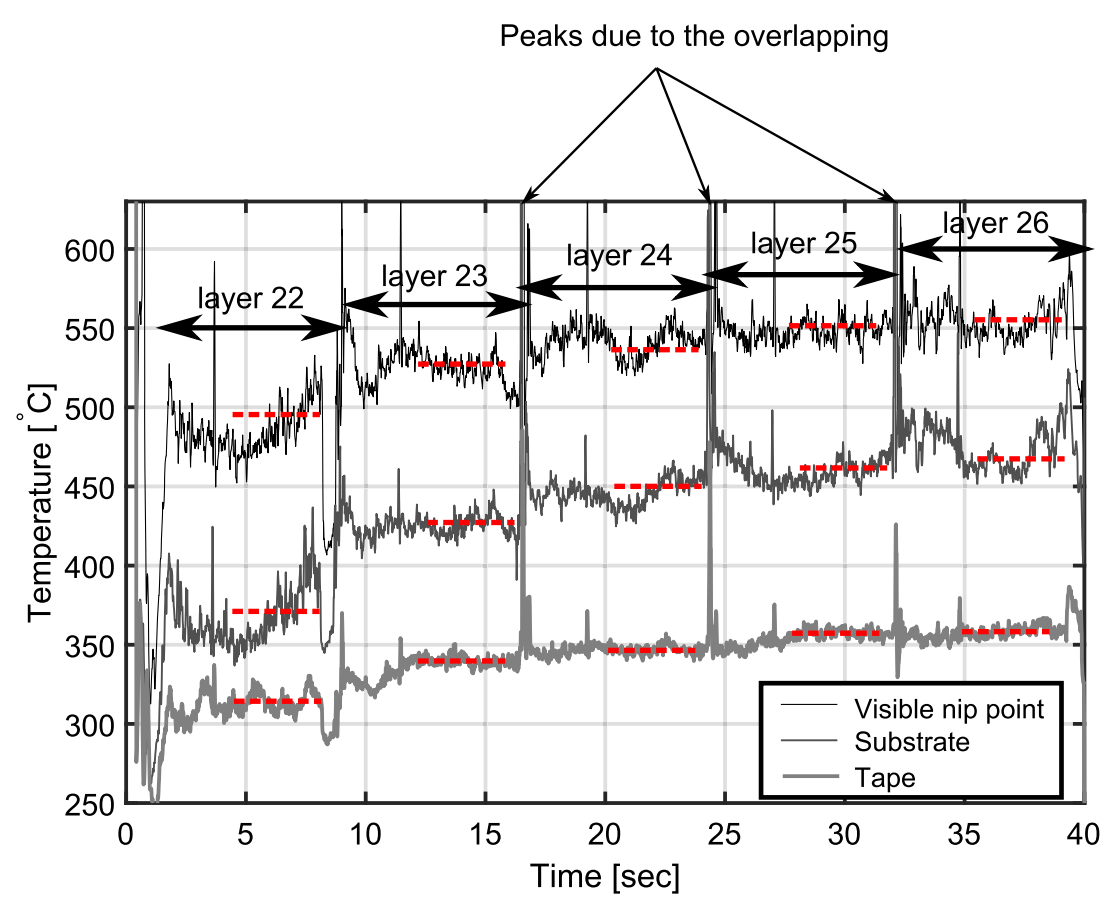


Fig. 9 a Pixel based temperature distribution in the winding $(y-)$ direction. b A schematic view showing the movement of the nip point location as the substrate thickness grew from a $x-z$ view

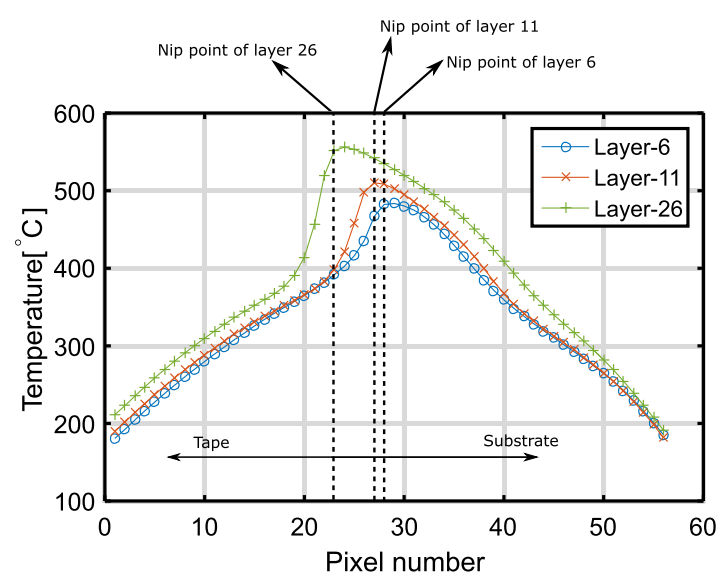

(a)

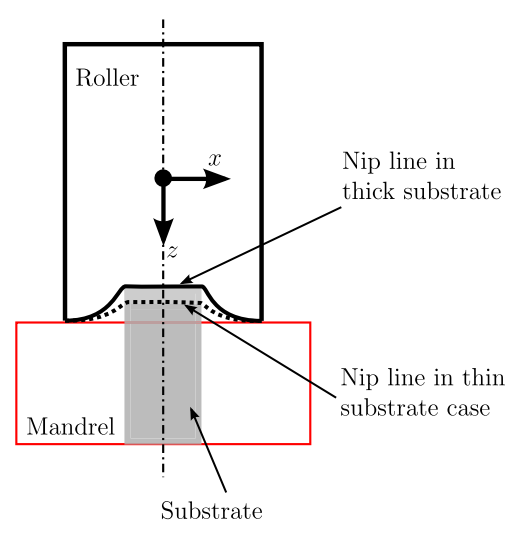

(b) in the literature $[12,33,36,39]$. A near-perfect contact was assumed at the substrate-mandrel interface, therefore a relatively high value for $h_{m}=4000 \mathrm{~W} \mathrm{~m}^{-2}{ }^{\circ} \mathrm{C}^{-1}$ was used. Although the roller temperature changes during the process due to laser heating, in this study $T_{\text {roller }}$ was assumed to be constant with a value of $50^{\circ} \mathrm{C}$ as used also in [33]. Besides [33], it was shown in [36] that a lower roller temperature was found to be closer to the experimental data based on the slope of the cooling curves in the consolidation region. In the present work, the total laser power was set to $400 \mathrm{~W}$ and the linear winding speed was $100 \mathrm{~mm} / \mathrm{s}$ as taken from the experiments.

Fig. 10 a The consolidation pressure distribution measured by pressure sensitive films placed between the compaction roller and substrate. b A schematic view to show the change in the consolidation region length of the thin and thick substrate and the nip point location from $y-z$ view

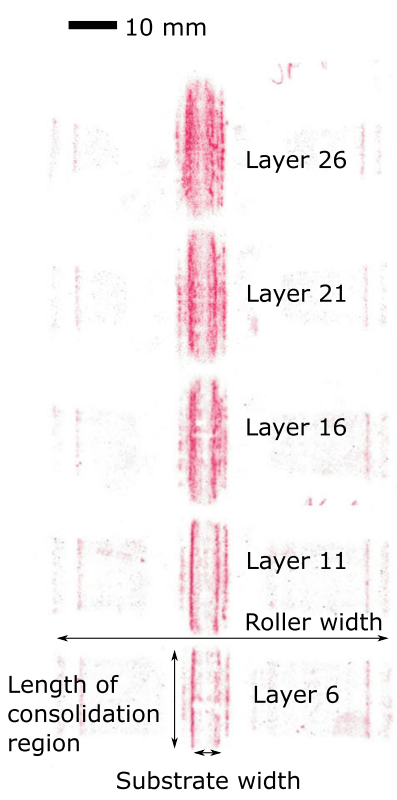

(a)

\section{Results and discussions}

Three composite rings were manufactured and Fig. 7 shows the resulting cross-section. It is seen that the top surface was slightly curved due to a non-linear distribution of the compaction force. As the ring got thicker during winding, the edges were prone to deform by the deformable roller at relatively high temperatures. This yielded a slightly wider composite ring than the expected nominal width of 6.35 $\mathrm{mm}$. The thickness of the cross-section at the center was found to be the same as the expected nominal thickness which was $26 \times 0.15 \mathrm{~mm}=3.9 \mathrm{~mm}$. However, the thickness

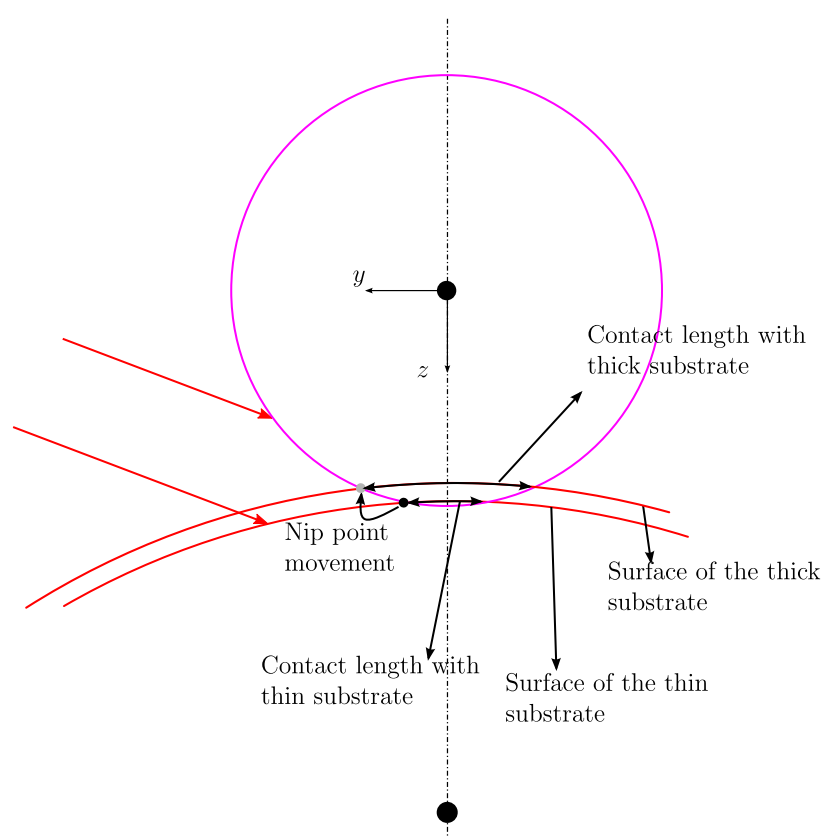

(b) 
at the edges was found to be approximately $2.9 \mathrm{~mm}$. Although the curved substrate surface might affect the absorbed laser heat flux across the width, the change in the substrate geometry was not taken into account in the process simulations. Based on the micrograph of the ring cross section as seen in Fig. 7, there was no void or porosity observed in between the wound layers. The measured tape and substrate temperatures are presented in the following.

\section{Temperature measurements}

The surface temperature of the substrate and tape was measured continuously by the thermal camera as indicated in Fig. 4a. To illustrate, the measured temperature as a function of time is shown in Fig. 8 for the continuous winding of layers 22 to 26 . Note that the substrate and tape temperatures are plotted for the 5th pixel away from the nip point at the width mid-plane. It took approximately $7.7 \mathrm{~s}$ to wind one layer as shown in Fig. 8. There was an increase of approximately $25{ }^{\circ} \mathrm{C}$ for the tape temperature while winding layers 22 to 26 . On the other hand, a larger increase in substrate and visible nip point temperatures were observed which were approximately $100{ }^{\circ} \mathrm{C}$ and $55{ }^{\circ} \mathrm{C}$, respectively. The overall increase in the temperature was mainly due to the continuous heating of the system during multiple windings. As expected, the increase in nip point temperature was in between the increase in substrate and tape temperatures. The temperature during the winding of the first layer of the five consecutive layers (e.g. layer 22 in Fig. 8) was found to vary because the winding was started after waiting the system got cooled to room temperature. After winding the other layers (e.g. layers 23-26), the substrate, tape and nip point temperature were found to vary less as compared with the first layer (e.g. layer 22). The peaks in between the layers were related to the overlapping of the incoming tape with the already deposited substrate [15]. The trend in temperature evolution presented in Fig. 8 was the same as in winding of layers $2-6,7-11,12-16$ and 17-21.

In order to evaluate the substrate and tape temperature distribution per layer, the measured temperature during winding of each layer was averaged with respect to time. To illustrate, the temperature evolution was averaged at horizontal dashed lines indicated in Fig. 8 for layer 22 to 26 and this procedure was applied to all other layers for three winding experiments. The time-averaged temperature distributions on the substrate and tape are depicted in Fig. 9a for layers 6,11 and 26 to demonstrate the temperature distribution trend based on the pixel distribution presented in Fig. 4 in the $y$-direction. It is seen that the tape temperature increased rapidly near nip point which could be due to the IR rays reflected by the tape surface. In other words, the thermal camera receives both the IR rays emitted by the relatively cold tape surface and the reflected IR rays emitted from the relatively hot substrate surface close to the nip point [19]. In addition, it was also found in Fig. 9 that the location of the visible nip point became closer to the tape side as the substrate got thicker. This was due to the fact that the position of the roller center was fixed by the AFP machine as the substrate radius became larger. This mechanism is explained schematically in Fig. 9b from the thermal camera point of view. The initial roller indentation was measured approximately as $2 \mathrm{~mm}$ for a 1layer thick substrate. It became larger as the new layers wound on top of the already placed layers which locally changed the visible nip point location. Therefore, the change in the visible nip point location has to be taken into account for a reliable analysis of the nip point temperature by using
Fig. 11 The nip point temperature evolution during consecutive ring winding. The measured tape and substrate nip point temperatures are belonging to 1 st pixel away from the visible nip point. Refer to Fig. 9 for pixel based temperature distribution and the location of the visible nip point for selected layers

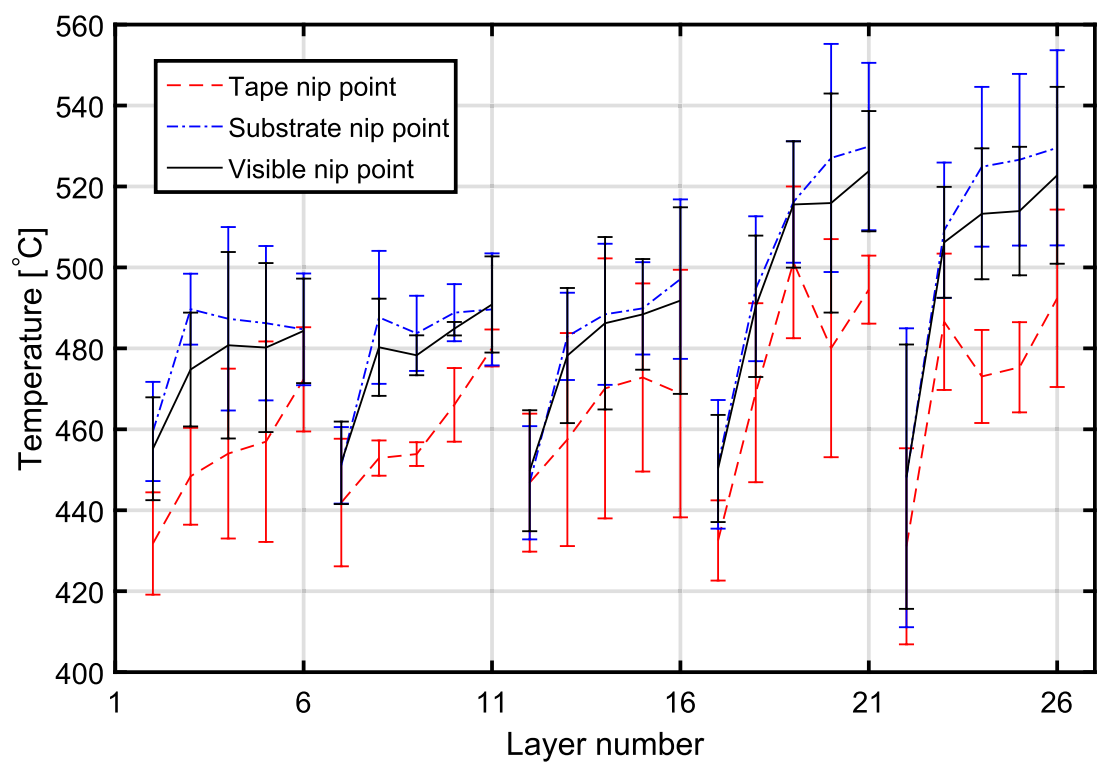


Fig. 12 Normalized incident heat flux considering the anisotropic reflection of the (a) substrate and (b) tape surface with $I=2 \mathrm{~mm}$. The averaged heat flux values along the width as a function of distance to the nip point for the (c) substrate and (d) tape considering individual energies absorbed in each reflection

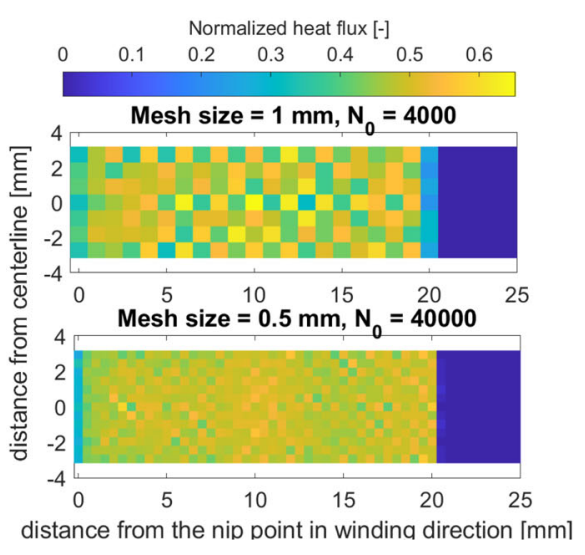

(a)

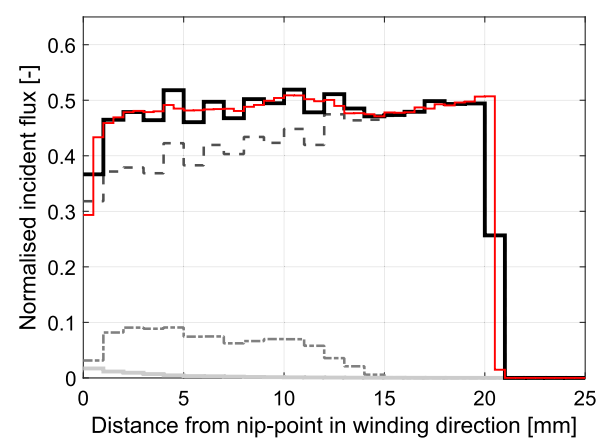

(c)

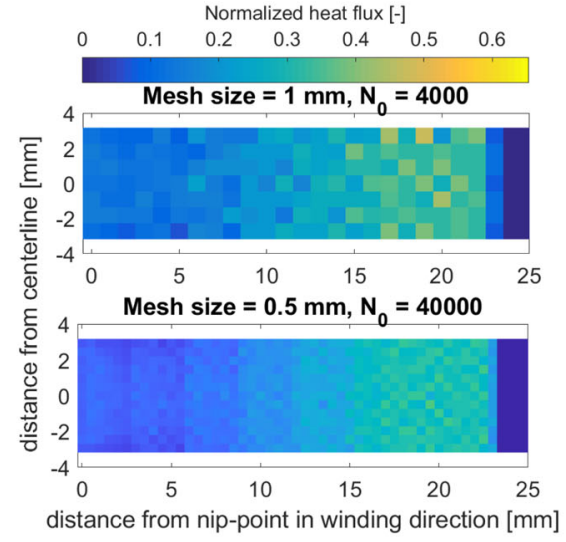

(b)

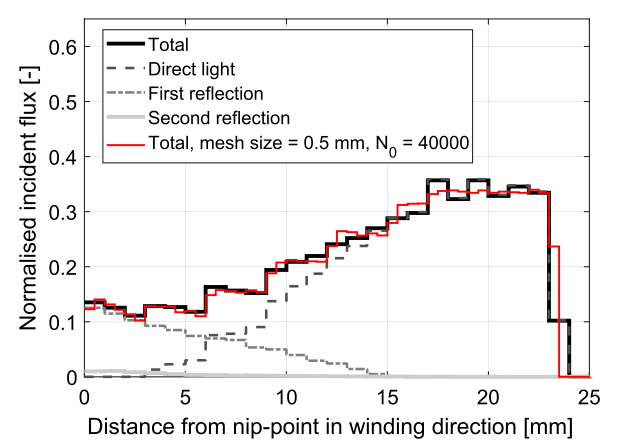

(d) the thermal camera. Another consequence of the increase in substrate thickness was the change in the consolidation area and the applied pressure on the substrate. The applied consolidation pressure was qualitatively obtained by using the pressure-sensitive films as shown in Fig. 10a for the layers $6,11,16,21$, and 26 . It is seen that the darker images were observed as the layer number increased and hence the applied force on the substrate increased as well, although, the compaction force was maintained constant by the pneumatic system. The increase in consolidation area and change in nip point position are schematically explained in Fig. 10b. The consolidation area increased from $16.8 \mathrm{~mm}$ for layer 6 to $24.4 \mathrm{~mm}$ for layer 26 .

The time-averaged visible, substrate, and tape nip point temperature evolution are depicted in Fig. 11 for consecutive winding of layers 2-6, 7-11, 12-16, 17-21 and
Fig. 13 The predicted temperature distribution on the (a) substrate and (b) tape surface at the heating region during winding of the second layer

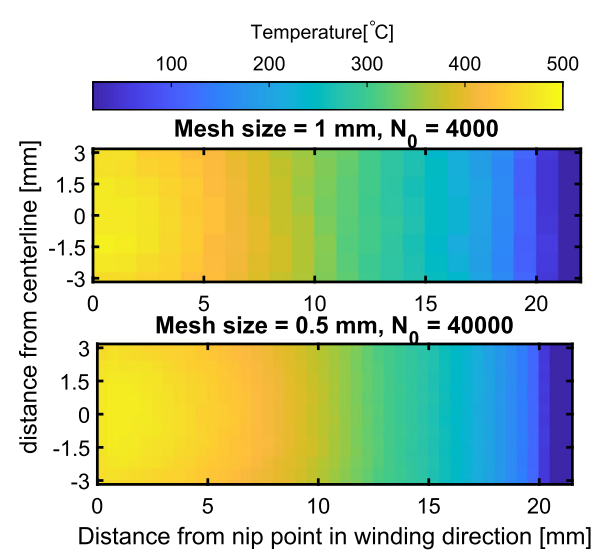

(a)

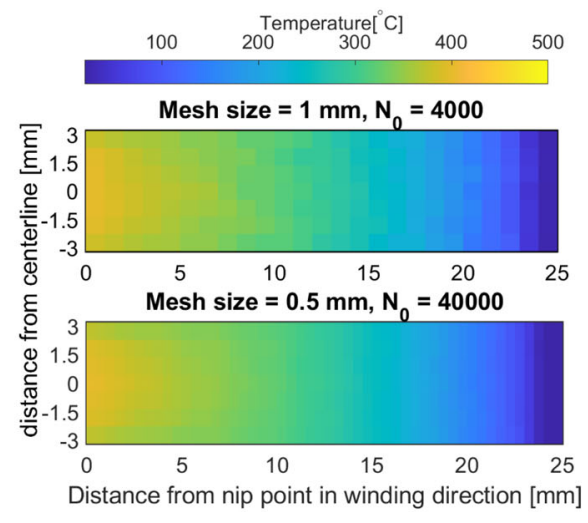

(b) 
22-26. The tape and substrate nip point temperatures were extracted from the 1st pixel away from the nip point as shown in Fig. 4a. The error bars indicate the standard deviation of the temperature values obtained during winding of three rings and the center of the error bars shows the corresponding mean temperature. It is seen that the time-averaged substrate nip point temperature of the first layers, i.e. layer 2, 7, 12, 17 and 22, reduced due to an increase in substrate thickness. On the other hand, these temperatures for the tape were almost the same because the thickness of the incoming tape remained the same. It is seen that as the substrate got thicker, the overall visible, tape, and substrate nip points temperatures increased. The increase in temperature during consecutive winding of 5 layers became larger as the layer number increased. For instance, the substrate temperature increase was found to be approximately $98{ }^{\circ} \mathrm{C}$ during winding of layers 22-26, whereas it was approximately $42{ }^{\circ} \mathrm{C}$ for layers $7-11$. This was due to the less heat loss to the mandrel as the substrate got thicker which resulted in a larger through-thickness thermal resistance. The increase in tape temperature during consecutive winding of 5 layers was found to be in the range of $40-50{ }^{\circ} \mathrm{C}$. This variation was less than the variation in substrate temperature since the incoming tape thickness was constant during winding. The maximum and minimum variation in substrate and tape temperatures among the three winding experiments was found to be $80{ }^{\circ} \mathrm{C}$ for layer-22 and $10^{\circ} \mathrm{C}$ for layer-7, respectively. The possible reasons for the variations in the temperature measurements within three rings production could be related to the local variation in material properties of the prepreg [44], local deconsolidation in the heated region and varying emissivity coefficient as a function of temperature [19] which was constant in the current configuration of the thermal camera.

\section{Process model predictions}

\section{Heat flux and temperature}

The predicted distribution of the absorbed heat flux using the 3D optical model is shown in Fig. 12a and b for winding of layer-2 $(I=2 \mathrm{~mm})$ in order to illustrate the typical output of the optical simulation. The utilized mesh size of $2 \mathrm{~mm}$ and the total number of rays $N_{0}=4000$ were found to have a sufficient accuracy as compared with the finer mesh size of $0.5 \mathrm{~mm}$ and $N_{0}=40000$ as also seen in Fig. $12 \mathrm{c}$ and d. It is seen that the length of the heated regions was $21 \mathrm{~mm}$ and $24 \mathrm{~mm}$ for the substrate and tape, respectively. Higher heat flux was predicted for the substrate than the tape due to a more perpendicular incident angle of laser rays at the direct hit which resulted in larger ray energy absorption according to Fresnel law [26]. The magnitude of heat flux reduced near the nip point region both for substrate and tape because the incident angle of the direct hit decreased as depicted in Fig. 3. The corresponding normalized heat flux distributions at the centerline of substrate and tape along the winding direction are shown in Fig. 12c and d. The normalization was done based on the power intensity of the laser source which was $1.3 \mathrm{~W} \mathrm{~mm}^{2}$. The total energy absorbed by the substrate surface consisted of the direct hit from the laser source and the rays from the first and second reflection as

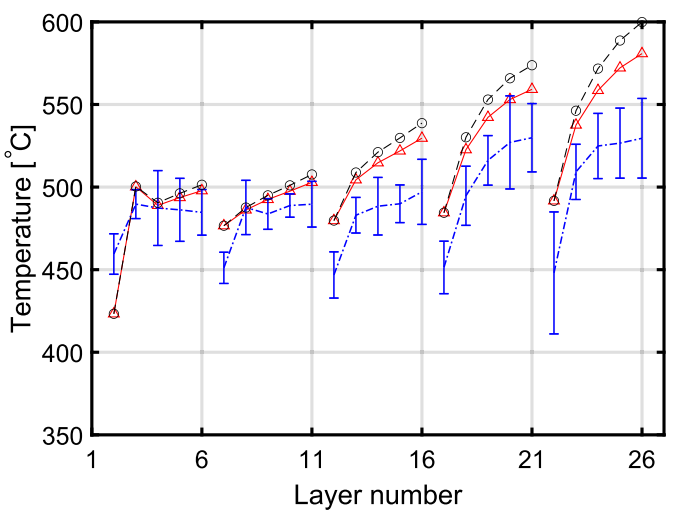

(a)

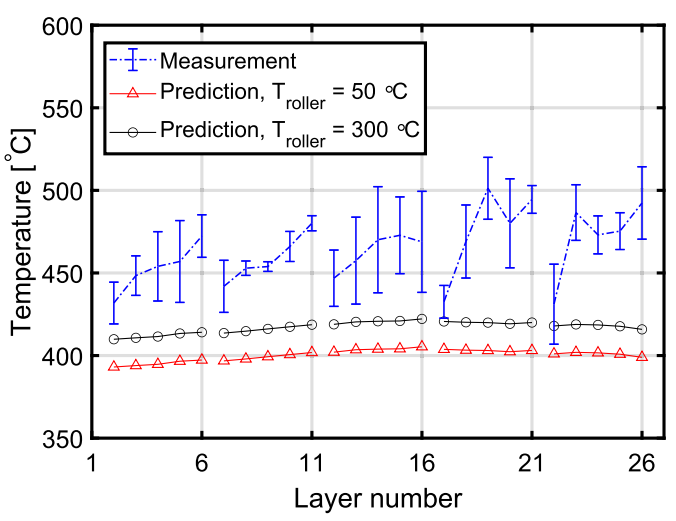

(b)

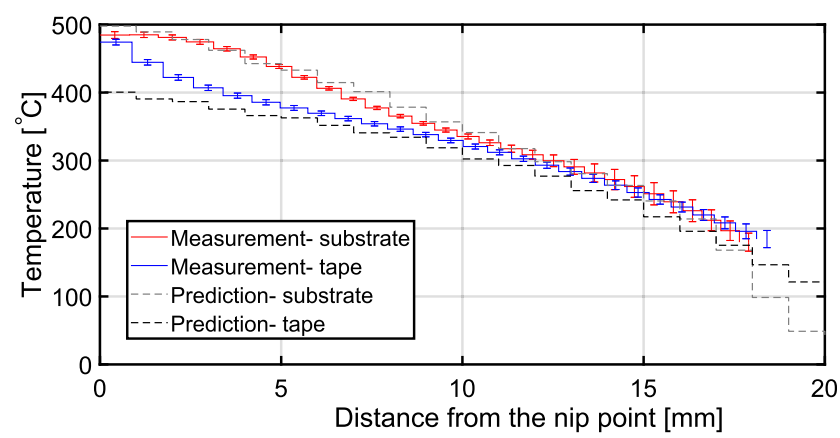

(c)

Fig. 14 Predicted and measured nip point temperatures for the (a) substrate and (b) tape. c Predicted and measured temperature distributions in the winding direction along the centerline of the substrate and tape during winding the 6th layer 
shown in Fig. 3. It is seen from Fig. $12 \mathrm{c}$ and $\mathrm{d}$ that the direct hit for substrate and tape contained approximately the $80 \%$ of the total heat flux. The first reflection covered a 15 $\mathrm{mm}$ length from the nip point for substrate and tape with approximately $28 \%$ of the total heat flux. On the other hand, the second reflection had approximately $2 \%$ of the total heat flux.

The corresponding temperature distribution for the substrate and tape obtained from the thermal model are shown in Fig. 13a and b for the current default mesh (mesh size of $1 \mathrm{~mm}$ and $N_{0}=4000$ ) and the finer mesh

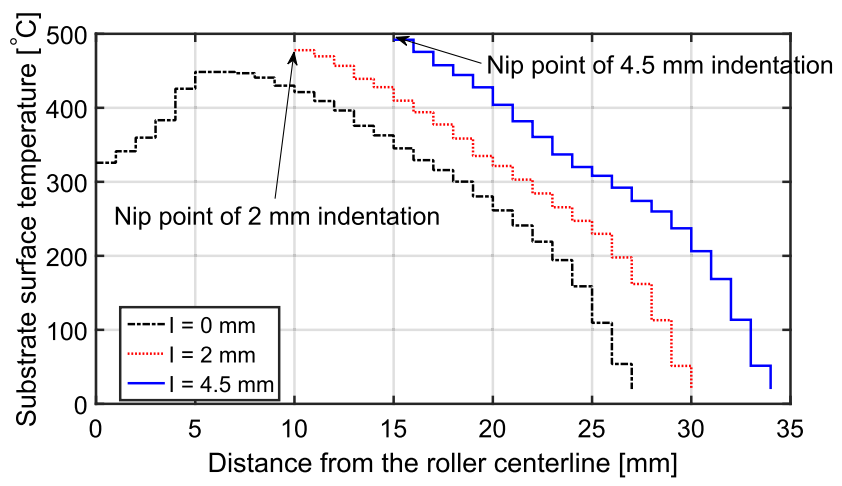

(a)

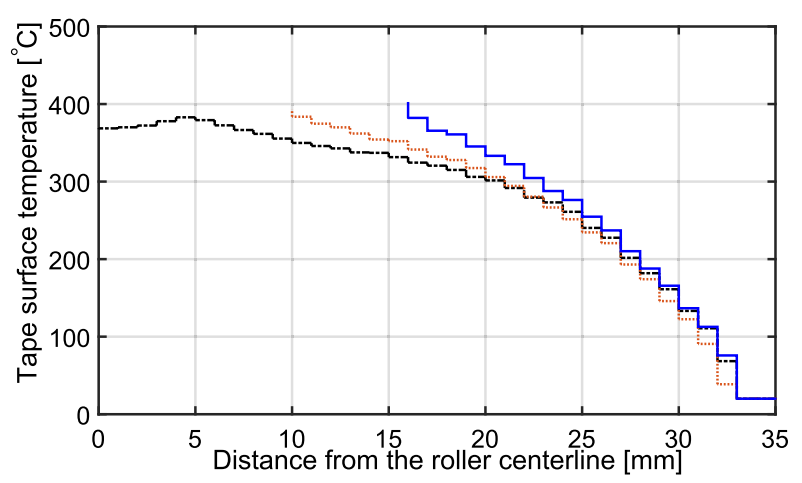

(b)

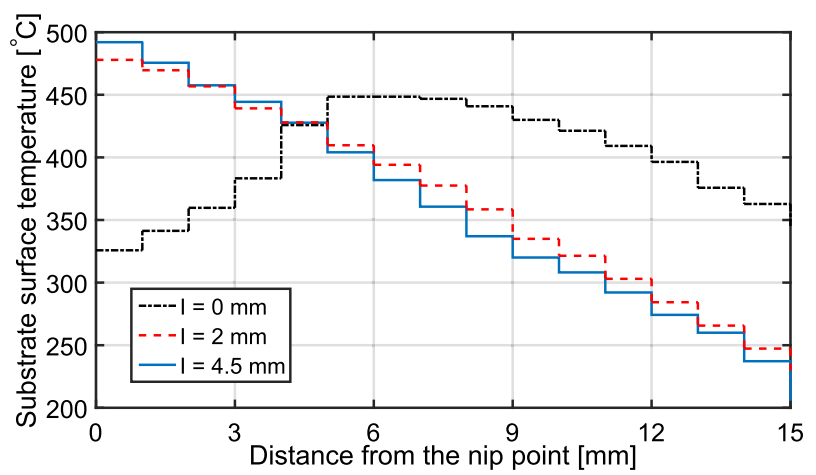

(c)

Fig. 15 Predicted temperature distribution on the surface in the winding direction at the width mid-plane during winding of layer 7 from the roller centerline for the (a) substrate and (b) tape. c The substrate temperature distribution from the actual nip point (mesh size of $0.5 \mathrm{~mm}$ and $N_{0}=40000$ ). It is seen that the results obtained from the default mesh and the finer mesh yielded a very close temperature distribution. The resulting temperature distribution was not uniform in the width direction, i.e. in the $x$-direction, due to anisotropic reflections. The tape temperature prior to the nip point was found to be lower than the substrate temperature due to a lower heat flux distribution for the tape, see Fig. 12c and $\mathrm{d}$. This observation was also the case in the measured temperature distribution depicted in Fig. 11.

The temperature predictions were made for all the layers from 2 to 26 using the optical-thermal model in which the roller indentation was increasing linearly from $2 \mathrm{~mm}$ to $5.75 \mathrm{~mm}$ to be compared with the experimental data. The corresponding results are presented in Fig. 14a and $\mathrm{b}$ for the substrate and tape nip points. The predictions confirm the experimental observation that the increase in substrate temperature was found to be larger during winding on thicker substrates. For instance, the predicted substrate temperature increase was $89^{\circ} \mathrm{C}$ and $26^{\circ} \mathrm{C}$ during winding of layers $22-26$ and layers $7-11$, respectively. In general, the developed process model captured the measured temperature evolution trend quite well for the substrate with overprediction up to $51{ }^{\circ} \mathrm{C}$ as the ring got thicker. According to Fig. 14b, the increase in tape temperature during consecutive winding was found to lower than the increase in substrate temperature as also observed by the measurements. The predicted tape temperature increase was $5{ }^{\circ} \mathrm{C}$ during winding of layers 7-11 and it was almost constant during winding of layers 22-26. A larger mismatch in the measured and predicted nip point temperature was found for the tape with a range of $38-98{ }^{\circ} \mathrm{C}$.

The measured and predicted centerline temperature profiles along the winding direction is given in Fig. 14c during winding of layer 6 . It is seen that the predicted substrate temperature distribution agreed well with the measurement. On the other hand, the predicted tape distribution was lower than the measured one near the nip point. This could be due to the employment of relatively simple roller geometry and deformation which was more complex in reality, i.e. the deformation is non-circular. Besides, the utilized tape-roller convection coefficient value could also play a role for the obtained mismatch in the predicted and measured tape temperature near the nip point. In addition, a constant roller temperature $T_{\text {roller }}=50{ }^{\circ} \mathrm{C}$ [33] was used in the thermal model, however it can increase up to $300^{\circ} \mathrm{C}$ [36]. This would affect the heat transfer at the tape-roller interface significantly though the averaged nip point temperature would not be affected significantly according to [36]. To illustrate this, the process simulations were conducted with $T_{\text {roller }}=300{ }^{\circ} \mathrm{C}$ and the results are depicted in Figs. 14a and $\mathrm{b}$ for the nip point temperature of the substrate and tape for each layer, respectively. It is seen 
Fig. 16 A schematic view of the change in the heating length of the tape and substrate considering the effect of roller indentation. The dashed geometry corresponds to higher value of roller indentation

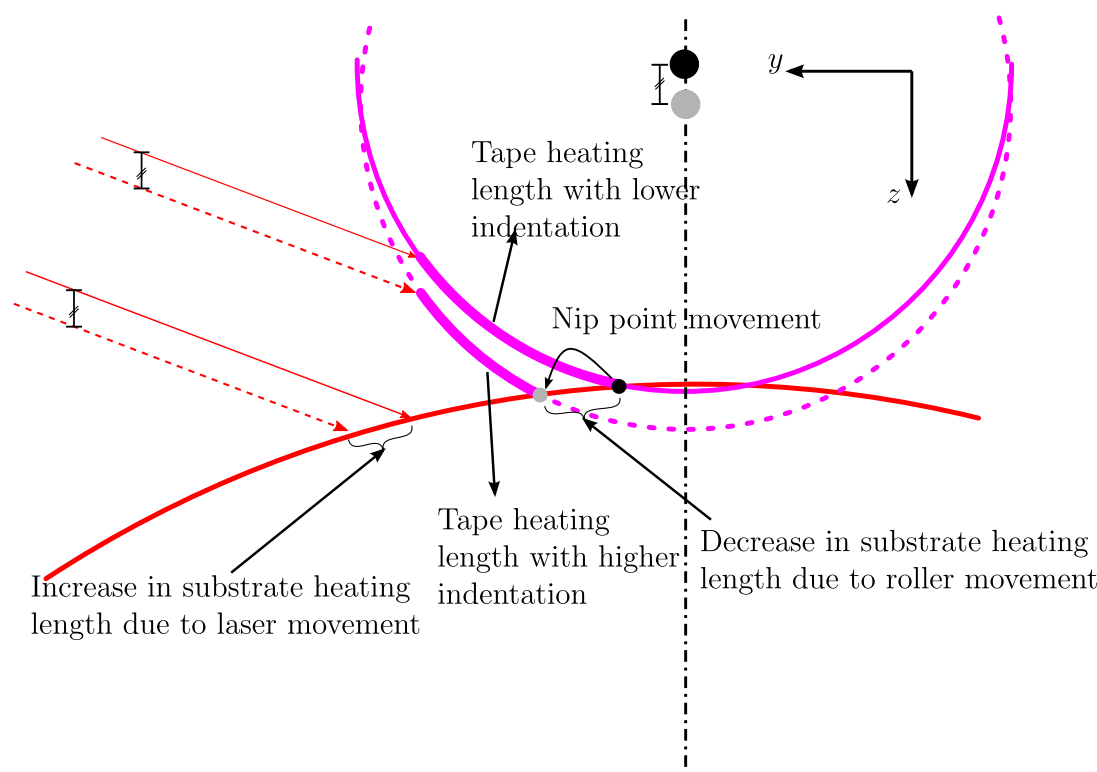

that the overall tape temperature at the nip point increased approximately $17^{\circ} \mathrm{C}$ as compared to the case with $T_{\text {roller }}=$ $50{ }^{\circ} \mathrm{C}$. A maximum of $20^{\circ} \mathrm{C}$ difference was obtained for the substrate temperature during winding of layer 26 with varying roller indentation. The temperature difference was negligible during winding of layers 2-11. This indicated that the effect of roller temperature on the substrate nip point temperature was more dominant for larger roller indentation values.

\section{Effect of roller indention}

The influence of the roller deformation on the temperature evolution was investigated using the proposed opticalthermal model. Three constant roller indentation values $I=0,2$ and $4.5 \mathrm{~mm}$ were considered in the parameter analysis. To illustrate the predicted temperature distribution, the results from winding of layer-7 on a 6-layers thick substrate are depicted in Figs. 15a and b for the substrate and tape surface, respectively. A schematic description of roller indention is plotted in Fig. 16 where the substrate is stationary and the roller together with the laser source moved toward the substrate. This modeling approach is basically the same as the case of growing substrate with stationary roller and laser source (refer to Fig. 10b). The nip point temperature increased approximately by $167^{\circ} \mathrm{C}(51 \%)$ for the substrate, i.e. from $325^{\circ} \mathrm{C}$ to $492^{\circ} \mathrm{C}$, and by $35^{\circ} \mathrm{C}(9 \%)$ for the tape, i.e. from $367^{\circ} \mathrm{C}$ to $402^{\circ} \mathrm{C}$, by increasing $I$ from $0 \mathrm{~mm}$ to $4.5 \mathrm{~mm}$. It is seen that the shadow area where the temperature drops close to the nip point diminished for $I=2 \mathrm{~mm}$ and $4.5 \mathrm{~mm}$ both for tape and substrate. Therefore, roller indentation resulted in a shift in the nip point location which was approximately $15 \mathrm{~mm}$ and $16 \mathrm{~mm}$ by increasing $I$ from $0 \mathrm{~mm}$ to $4.5 \mathrm{~mm}$ for substrate and tape, respectively. In addition, the roller indentation affected also the total consolidation length as mentioned in
Fig. 17 The evolution of the substrate nip point temperature for various roller indentation $(I)$ values

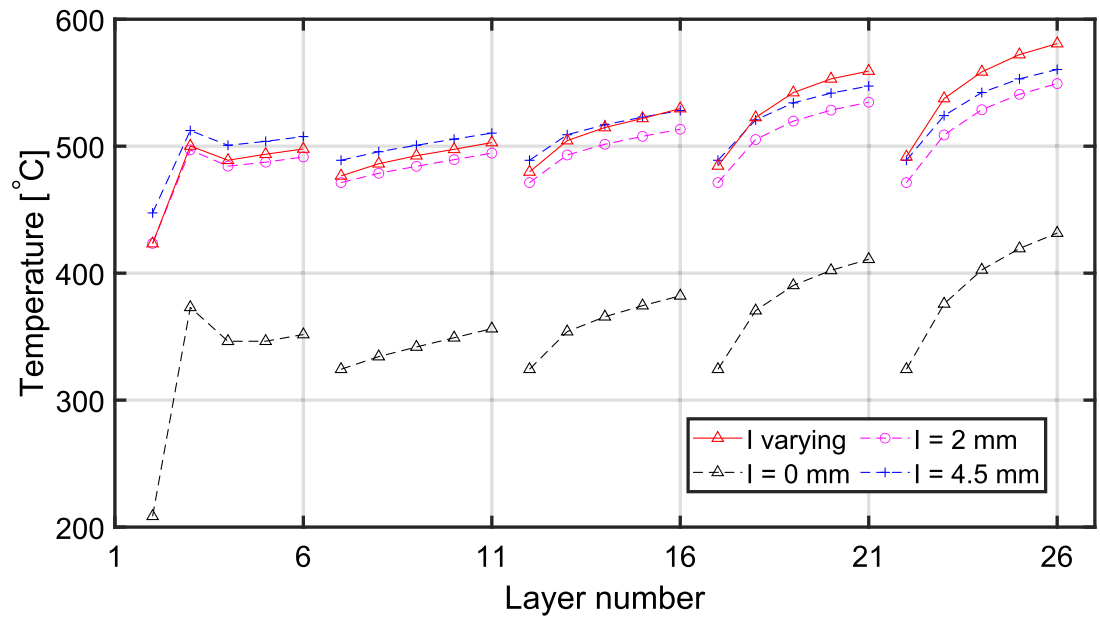


Fig. 18 The effect of the roller indentation on the nip point temperature (averaged along the width direction), total heated length, total absorbed heat and local absorbed heat at the nip point (averaged along the width direction) for the tape (left) and substrate (right)

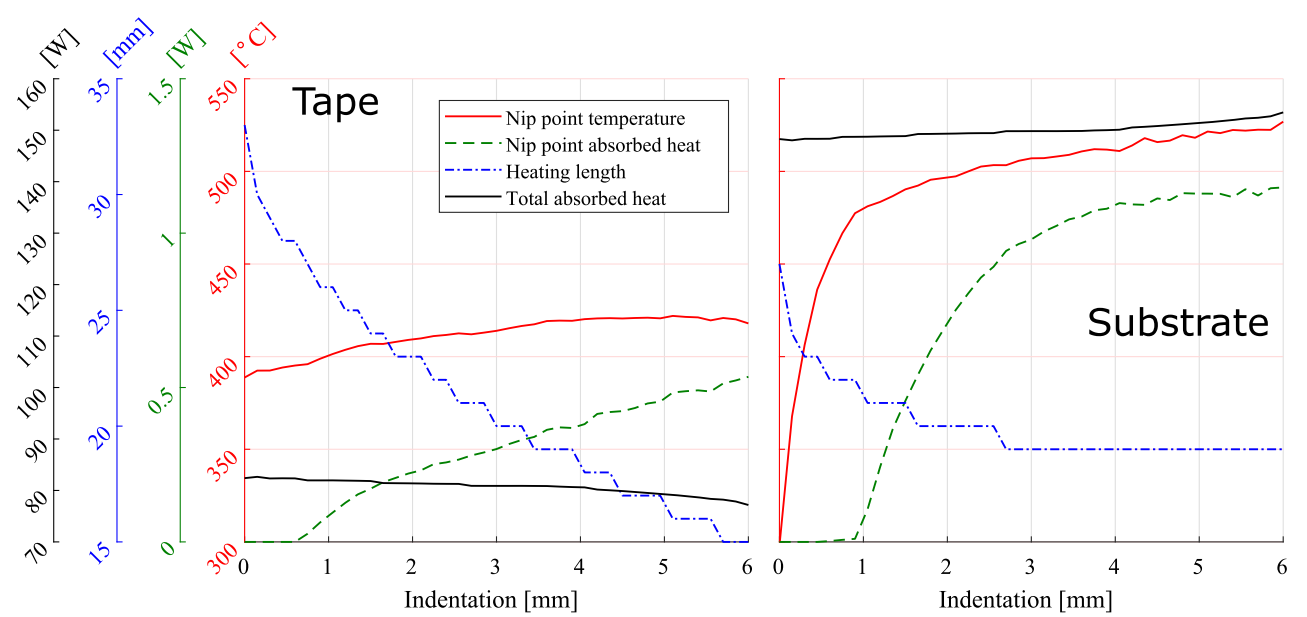

Fig. 10. The contact length of the consolidation region for $I=2 \mathrm{~mm}$ and $4.5 \mathrm{~mm}$ was $21 \mathrm{~mm}$ and $31 \mathrm{~mm}$, respectively. An increase of $7 \mathrm{~mm}$ in the substrate heating region was obtained as $I$ was increased from $0 \mathrm{~mm}$ to $4.5 \mathrm{~mm}$. This was due to the movement of the laser source which was connected to the roller center via the tape laying head as schematically depicted in Fig. 16. Considering both the nip point and laser movement effects the heating length reduced from 27 to $19 \mathrm{~mm}$ on the substrate and from 33 to $17 \mathrm{~mm}$ on the tape surfaces by increasing $I$ from 0 to $4.5 \mathrm{~mm}$. Although the heated lengths of tape and substrate decreased as the roller deformation increased, the laser incident angles near the nip point became more perpendicular to the tape and substrate surfaces which resulted in larger temperatures.

The substrate temperature distribution shown in Fig. 15a is re-plotted in Fig. 15c by locating the nip point at $y=$ $0 \mathrm{~mm}$. The temperature at the nip point was lower for lower indention values as explained earlier, however, after approximately $5 \mathrm{~mm}$, lower indentation values resulted in higher temperatures since the heating length before this point was larger. The mean surface temperature was approximately $427^{\circ} \mathrm{C}$ for all the roller indentation values

Table 5 The predicted temperature difference for the selected layers as a function of roller indentation $(I)$ change for tape and substrate nip points

\begin{tabular}{|c|cc|cc|}
\hline \multirow{2}{*}{ Layer number } & \multicolumn{4}{|c|}{ Measuring area } \\
\cline { 2 - 5 } & \multicolumn{4}{|c|}{$I$ change $(\mathbf{m m})$} \\
\cline { 2 - 5 } & $0 \rightarrow 2$ & $2 \rightarrow 4.5$ & $0 \rightarrow 2$ & $2 \rightarrow 4.5$ \\
\hline 6 & & & $139.9^{\circ} \mathrm{C}$ & $16.1^{\circ} \mathrm{C}$ \\
11 & & & $138.3^{\circ} \mathrm{C}$ & $15.8^{\circ} \mathrm{C}$ \\
16 & $26^{\circ} \mathrm{C}$ & $9^{\circ} \mathrm{C}$ & $131.2^{\circ} \mathrm{C}$ & $14.8^{\circ} \mathrm{C}$ \\
21 & & & $123.7^{\circ} \mathrm{C}$ & $12.7^{\circ} \mathrm{C}$ \\
26 & & & $117.7^{\circ} \mathrm{C}$ & $11.1^{\circ} \mathrm{C}$ \\
\hline
\end{tabular}

approximately at 4 - $5 \mathrm{~mm}$ away from the nip point as seen in Fig. $15 \mathrm{c}$. In other words, the mean surface temperature in the range of $4-5 \mathrm{~mm}$ from the nip point was not affected by the roller indentation and the effect of change in the input heat flux distribution was therefore negligible.

The corresponding evolution of the substrate nip point temperature during continuous winding with different roller indentation values are depicted in Fig. 17. It is seen that the nip point temperature increased with an increase in $I$. The increase in temperature during 5 consecutive windings was found to be highest for $I=0 \mathrm{~mm}$ because there was no heat loss at the substrate-roller interface which resulted in higher heat accumulation in the substrate. The predicted variation in substrate nip point temperature due to the change in $I$ was found to be approximately in the range of $20-30^{\circ} \mathrm{C}$. This was approximately $5^{\circ} \mathrm{C}$ for the tape nip point temperature.

In order to interpret the effect of roller indentation on the process temperature more elaborately, the total heated length, the total absorbed power and the local absorbed power at the nip point were investigated for different indentation values as shown in Fig. 18. As aforementioned, the total heated length of the tape and substrate decreased, however the local absorbed heat at the nip point increased due to an increase in the incident angle of the incoming rays as well as the reduction in the shadowed region. The increase in the incident angle was larger for the substrate than the tape due to position of the laser source which was oriented more towards the substrate as seen in Fig. 3. As a result, the total absorbed heat slightly increased for the substrate though the total heated length decreased. On the other hand, a slight decrease in the total absorbed heat was the case for the tape as the roller indentation increased due to larger decrease in the total heated length. This yielded a more rapid increase in the substrate temperature than the tape temperature as the roller indented more. Note that until $1 \mathrm{~mm}$ of roller indentation, the shadowing effect was present for both tape and substrate. The step-wise decrease 
Fig. 19 Measured and predicted substrate nip point temperatures with different substrate-roller convection coefficient $\left(h_{r}\right)$ during continuous winding

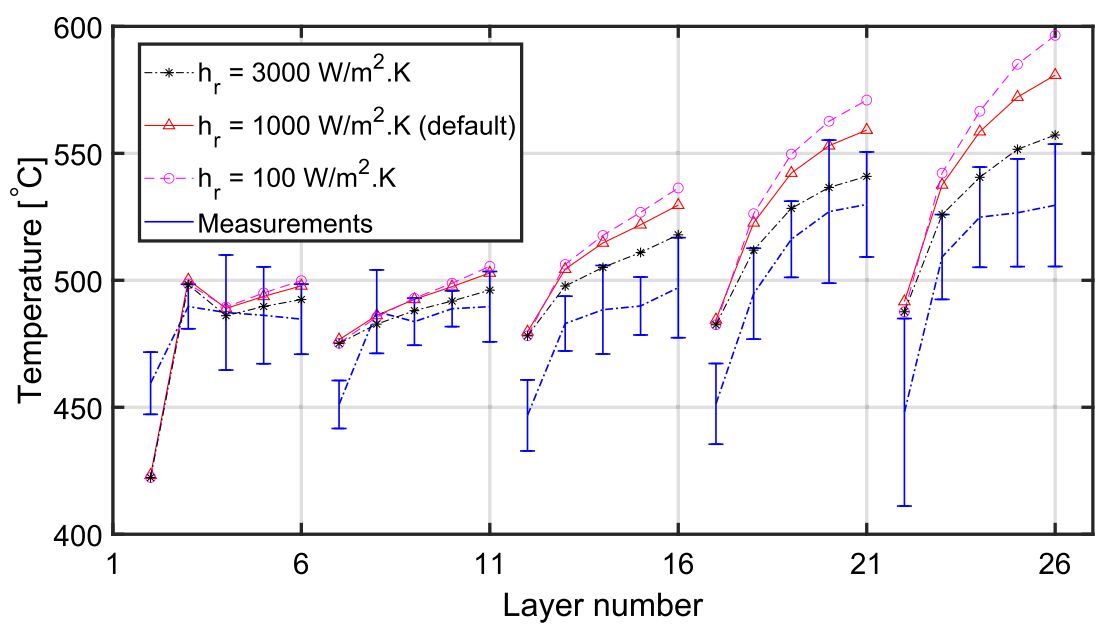

in the total length was due to the used mesh size in the thermal model. Finer mesh would result in a finer total length evolution as the roller indentation increases.

The effect of roller indentation on the temperature variation is quantified in Table 5 for the substrate and tape nip point temperature during continuous windings. By the increment of $I$ from 0 to $2 \mathrm{~mm}$, a more noticeable change in temperature was predicted as compared with the increment from 2 to 4.5 $\mathrm{mm}$. For the tape nip point, the change in the temperature was constant for all the layers since the tape thickness remained constant and a steady-state temperature was the case for the tape. However, the substrate temperature variation due to the change in $I$, tended to smaller values (not necessarily the absolute value) as the substrate got thicker. For instance, by increasing the indentation from 0 to $2 \mathrm{~mm}$, the temperature increment dropped from 139.9 to $117.7^{\circ} \mathrm{C}(39.6 \%$ to $27.4 \%)$ during the continuous winding of layers 6 and 26, respectively. The roller compaction length was larger with larger $I$ values, therefore, the consecutive heat loss to the roller was also higher leading to the mentioned drop in the temperature difference.

\section{Effect of substrate-roller convection coefficient $\left(h_{r}\right)$}

In Section 1, it was observed that the growth in substrate thickness affected the applied force and consolidation length on the substrate substantially. This can result in a change in $h_{r}$ at the roller-substrate interface which directly influences the heat loss from the substrate to the roller. The effect of $h_{r}$ on the predicted substrate temperature for each layer during continuous winding is shown in Fig. 19. The effect of $h_{r}$ on the temperature variation was found to be more dominant for the thicker substrates as compared with thinner substrates since the major heat loss for thinner substrates took place at the substrate-mandrel interface instead of the substrate-roller interface. For instance, the substrate nip point temperature difference for layers 21 and
26 were $47^{\circ} \mathrm{C}(9.5 \%)$ and $31^{\circ} \mathrm{C}(5.7 \%)$ considering $h_{r}=100$ $\mathrm{W} \mathrm{m}{ }^{-2}{ }^{\circ} \mathrm{C}^{-1}$ and $h_{r}=3000 \mathrm{~W} \mathrm{~m}^{-2}{ }^{\circ} \mathrm{C}^{-1}$. The measured temperature evolutions agreed better with the predictions with higher $h_{r}$ as the substrate got thicker. This confirms the increase in consolidation pressure for thicker substrates observed by the pressure-sensitive films in Fig 10. Higher consolidation pressure indicates a lower thermal contact resistance at the roller-substrate interface which results in higher $h_{r}$ values.

\section{Conclusion}

The evolution of the temperature distribution during consecutive winding of multiple C/PEEK prepreg layers was investigated experimentally and numerically. Relatively thick C/PEEK rings with 26 layers were manufactured using the LATW process with inline temperature measurements using a thermal camera. A coupled optical-thermal model was used to predict the laser irradiation and reflections, heat flux distributions and resulting temperature distributions on the incoming tape and substrate surfaces. The anisotropic reflections of the incoming laser light were considered in the optical model. The process model was first validated and verified by comparing the measured surface temperature with numerical predictions. The trends of the predicted tape and substrate temperatures were found to agree well with the measurements. The increase in substrate temperature was found to be larger during winding on thicker substrates due to the fact that the heat loss to the mandrel became smaller. The tape temperature increase during consecutive winding was found to be lower than the substrate temperature increase as a general trend. The varying roller deformation or indention had a significant effect on the surface heat flux distribution together with the total heated length and consequently on the nip point temperatures. The tape nip point temperature increased slightly with an 
increase in roller deformation during consecutive winding. On the other hand, a larger temperature increase was found for the substrate with an increase in roller deformation mainly due to the reduction in the shadow region and the larger increase in the incident angle of the incoming rays near the nip point. However, in the range of $4-5 \mathrm{~mm}$ from the nip point the effect of roller indentation variation on the temperature was negligible. The pressure-sensitive films indicated that the consolidation pressure and the contact length between the substrate and roller increased during the winding process. The effect of the variation in the substrateroller convection coefficient $\left(h_{r}\right)$ was found to be more dominant on the variation in substrate nip point temperature for relatively thick substrates.

Acknowledgements This project was funded by the European Union's Horizon 2020 research and innovation program under Grant Agreement 678875. The dissemination of the project reflects only the opinion of the authors and the Commission is not responsible for the use of the information contained therein.

\section{Compliance with Ethical Standards}

Conflict of interests The authors declare that they have no conflict of interest.

Open Access This article is licensed under a Creative Commons Attribution 4.0 International License, which permits use, sharing, adaptation, distribution and reproduction in any medium or format, as long as you give appropriate credit to the original author(s) and the source, provide a link to the Creative Commons licence, and indicate if changes were made. The images or other third party material in this article are included in the article's Creative Commons licence, unless indicated otherwise in a credit line to the material. If material is not included in the article's Creative Commons licence and your intended use is not permitted by statutory regulation or exceeds the permitted use, you will need to obtain permission directly from the copyright holder. To view a copy of this licence, visit http:// creativecommonshorg/licenses/by/4.0/.

\section{References}

1. Operating instructions thermoimager tim. Tech. rep., MicroEpsilon

2. (2019). Technical data sheet of airkap-1 polyimide high temperature pressure sensitive tape. Tech. rep. Airtech

3. Ashikmin M, Premože S, Shirley P (2000) A microfacet-based BRDF generator. In: Proc. 27th annu. Conf. Comput. Graph. Interact. Tech. - SIGGRAPH '00. ACM Press, New York, pp 65-74, https://doi.org/10.1145/344779.344814

4. Chern BC, Moon TJ, Howell JR (2002) On-Line Processing of unidirectional fiber composites using radiative heating: i. Model J Compos Mater 36(16):1905-1934. https://doi.org/10.1177/0021998302036016236

5. Clancy G, Peeters D, Oliveri V, Jones D, O'Higgins RM, Weaver PM (2019) A study of the influence of processing parameters on steering of carbon fibre/PEEK tapes using laser-assisted tape placement. Compos Part B Eng 163(July 2018):243-251. https://doi.org/10.1016/j.compositesb.2018.11.033
6. Dedieu C, Barasinski A, Chinesta F, Dupillier JM (2017) About the origins of residual stresses in in situ consolidated thermoplastic composite rings. Int J Mater Form 10(5):779-792. https://doi.org/10.1007/s12289-016-1319-2

7. Denkena B, Schmidt C, Vóltzer K, Hocke T (2016) Thermographic online monitoring system for Automated Fiber Placement processes. Compos Part B Eng 97:239-243. https://doi.org/10.1016/j.compositesb.2016.04.076

8. Di Francesco M, Veldenz L, Dell'Anno G, Potter K (2017) Heater power control for multi-material, variable speed Automated Fibre Placement. Compos Part A Appl Sci Manuf 101:408-421. https://doi.org/10.1016/j.compositesa.2017.06.015

9. Gregory ED, Juarez PD (2018) In-situ thermography of automated fiber placement parts. In: AIP Conf. Proc., vol 1949, p 060005, https://doi.org/10.1063/1.5031551

10. Grouve W, Warnet L, Rietman B, Akkerman R (2012) On the weld strength of in situ tape placed reinforcements on weave reinforced structures. Compos Part A Appl Sci Manuf 43(9):1530-1536. https://doi.org/10.1016/j.compositesa.2012.04.010

11. Grouve W, Warnet L, Rietman B, Visser HA, Akkerman R (2013) Optimization of the tape placement process parameters for carbonPPS composites. Compos Part A Appl Sci Manuf 50:44-53. https://doi.org/10.1016/j.compositesa.2013.03.003

12. Guan X, Pitchumani R (2004) Modeling of spherulitic crystallization in thermoplastic tow-placement process: heat transfer analysis. Compos Sci Technol 64(9):1123-1134. https://doi.org/10.1016/j.compscitech.2003.08.011

13. Hassan N, Thompson JE, Batra RC, Hulcher AB, Song X, Loos AC (2005) A heat transfer analysis of the fiber placement composite manufacturing process. J Reinf Plast Compos 24(8):869-888. https://doi.org/10.1177/0731684405047773

14. Hosseini S, Baran I, Akkerman R (2017) Thermal modeling strategies for laser assisted tape winding (LATW) process. In: $21 \mathrm{St}$ int. conf. compos. mater. Xi'an, China

15. Hosseini SMA, Baran I, Akkerman R (2018) An experimental investigation on the thermal field of overlapping layers in laserassisted tape winding process. In: AIP Conf. Proc., vol 1960. AIP Publishing LLC, p 020011, https://doi.org/10.1063/1.5034812

16. James DL, Black WZ (1996) Thermal analysis of continuous Filament-Wound composites. J Thermoplast Compos Mater 9(1):54-75. https://doi.org/10.1177/089270579600900105

17. Khaled Y, Mehdi H (2017) Processing of thermoplastic matrix composites through automated fiber placement and tape laying methods. J. Thermoplast. Compos. Mater. p 089270571773830

18. Kim J, Moon TJ, Howell JR (2003) Transient thermal modeling of In-Situ curing during tape winding of composite cylinders. J Heat Transfer 125(1):137. https://doi.org/10.1115/1.1527912

19. Kok T (2018) On the consolidation quality in laser assisted fiber placement: the role of the heating phase. Ph.D. thesis, University of Twente, Enschede, The Netherlands

20. Kollmannsberger A, Lichtinger R, Hohenester F, Ebel C, Drechsler K (2018) Numerical analysis of the temperature profile during the laser-assisted automated fiber placement of CFRP tapes with thermoplastic matrix. J Thermoplast Compos Mater 31(12):1563-1586. https://doi.org/10.1177/0892705717738304

21. Krack M, Secanell M, Mertiny P (2011) Rotor design for High-Speed flywheel energy storage systems. In: Energy storage emerg. Era smart grids, may 2014, pp 41-68. intech, https://doi.org/10.5772/18359

22. Li Z, Yang T, Du Y (2015) Dynamic finite element simulation and transient temperature field analysis in thermoplastic composite tape lay-up process. J Thermoplast Compos Mater 28(4):558-573. https://doi.org/10.1177/0892705713486135

23. Lichtinger R, Hórmann P., Stelzl D, Hinterhỏlzl R. (2015) The effects of heat input on adjacent paths during Automated 
Fibre Placement. Compos Part A Appl Sci Manuf 68:387-397. https://doi.org/10.1016/j.compositesa.2014.10.004

24. Marsh G (2011) Automating aerospace composites production with fibre placement. Reinf Plast 55(3):32-37. https://doi.org/10.1016/S0034-3617(11)70075-3

25. Orth T, Krahl M, Parlevliet P, Modler N (2018) Optical thermal model for LED heating in thermoset-automated fiber placement. Adv Manuf Polym Compos Sci 4(3):73-82. https://doi.org/10.1080/20550340.2018.1507798

26. Reichardt J, Baran I, Akkerman R (2018) New analytical and numerical optical model for the laser assisted tape winding process. Compos. Part A Appl. Sci Manuf

27. Schaefer P, Gierszewski D, Kollmannsberger A, Zaremba S, Drechsler K (2017) Analysis and improved process response prediction of laser- assisted automated tape placement with PA-6/carbon tapes using Design of Experiments and numerical simulations. Compos Part A Appl Sci Manuf 96:137-146. 10.1016/j.compositesa.2017.02.008

28. Schakel M, Hosseini SA, Janssen H, Baran I, Brecher C (2019) Temperature analysis for the laser-assisted tape winding process of multi-layered composite pipes. Procedia CIRP 85:171-176. https://doi.org/10.1016/j.procir.2019.09.003

29. Schakel M., McNab J, Dodds N, Peters T, Janssen H, Brecher C (2018) Data collection and analysis for the creation of a digital shadow during the production of thermoplastic composite layers in unbonded flexible pipes. In: Proc. ASME 2018 37th int. Conf. Ocean. Offshore arct. Eng. ASME, https://doi.org/10.1115/OMAE2018-77011

30. Schmidt C, Denkena B, Vòltzer K, Hocke T (2017) Thermal Image-based Monitoring for the Automated Fiber Placement Process. Procedia CIRP 62:27-32. https://doi.org/10.1016/j.procir.2016.06.058

31. Slange TK, Warnet L, Grouve W, Akkerman R (2018) Deconsolidation of c/PEEK blanks: on the role of prepreg, blank manufacturing method and conditioning. Compos Part A Appl Sci Manuf 113(3):189-199. https://doi.org/10.1016/j.compositesa.2018.06.034

32. Sobol' I. (1967) On the distribution of points in a cube and the approximate evaluation of integrals. USSR Comput Math Math Phys 7(4):86-112. https://doi.org/10.1016/0041-5553(67)90144-9

33. Stokes-Griffin C, Compston P (2015) A combined optical-thermal model for near-infrared laser heating of thermoplastic composites in an automated tape placement process. Compos Part A Appl Sci Manuf 75:104-115. https://doi.org/10.1016/j.compositesa.2014.08.006

34. Stokes-Griffin C, Compston P (2015) Optical characterisation and modelling for oblique near-infrared laser heating of carbon fibre reinforced thermoplastic composites. Opt Lasers Eng 72:1-11. https://doi.org/10.1016/j.optlaseng.2015.03.016

35. Stokes-Griffin C, Compston P (2016) Investigation of sub-melt temperature bonding of carbon-fibre/PEEK in an automated laser tape placement process. Compos Part A Appl Sci Manuf 84:1725. https://doi.org/10.1016/j.compositesa.2015.12.019

36. Stokes-Griffin C, Compston P, Matuszyk TI, Cardew-Hall MJ (2015) Thermal modelling of the laser-assisted thermoplastic tape placement process. J Thermoplast Compos Mater 28(10):14451462. https://doi.org/10.1177/0892705713513285

37. Stokes-Griffin C, Kollmannsberger A, Compston P, Drechsler $\mathrm{K}$ (2019) The effect of processing temperature on wedge peel strength of CF/PA 6 laminates manufactured in a laser tape placement process. Compos Part A Appl Sci Manuf 121:84-91. https://doi.org/10.1016/j.compositesa.2019.02.011

38. Takahashi K, Kitade S, Morita H (2002) Development of high speed composite flywheel rotors for energy storage systems. Adv Compos Mater 11(1):40-49. 10.1163/156855102753613273

39. Toso YM, Ermanni P, Poulikakos D (2004) Thermal Phenomena in Fiber-reinforced Thermoplastic Tape Winding process: Computational Simulations and Experimental Validations. J Compos Mater 38(2):107-135. https://doi.org/10.1177/0021998304038651

40. Weiler T, Emonts M, Wollenburg L, Janssen H (2018) Transient thermal analysis of laser-assisted thermoplastic tape placement at high process speeds by use of analytical solutions. J Thermoplast Compos Mater 31(3):311-338. https://doi.org/10.1177/0892705717697780

41. Weiler T, Striet P, Voell A, Stollenwerk J, Janssen H, Emonts M (2018) Tailored irradiation by vcsel for controlled thermal states in thermoplastic tape placement. In: Laser 3d manufacturing V, vol 10523, p 105230e. International society for optics and photonics

42. Zaami A, Baran I, Akkerman R (2017) Numerical modeling of laser assisted tape winding process. In: AIP Conf. Proc., Dublin, $\mathrm{p}$ 180004, https://doi.org/10.1063/1.5008209

43. Zaami A, Baran I, Akkerman R (2018) Non-hoop winding effect on bonding temperature of laser assisted tape winding process. In: AIP Conf. Proc., vol 1960, p 020041, https://doi.org/10.1063/1.5034842

44. Zaami A, Schakel M., Baran I, Bor TC, Janssen H, Akkerman $\mathrm{R}$ (2019) Temperature variation during continuous laser-assisted adjacent hoop winding of type-IV pressure vessels: An experimental analysis. J. Compos. Mater. p 002199831988410

Publisher's note Springer Nature remains neutral with regard to jurisdictional claims in published maps and institutional affiliations. 